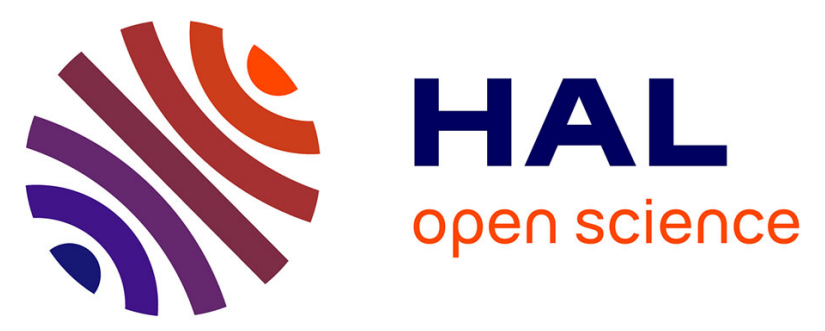

\title{
Hydraulic and chemical pulse tests in a shut-in chamber imbedded in an argillaceous formation: Numerical and experimental approaches
}

P. Rousseau-Gueutin, J. Goncalves, M. Cruchaudet, G. de Marsily, S. Violette

\section{- To cite this version:}

P. Rousseau-Gueutin, J. Goncalves, M. Cruchaudet, G. de Marsily, S. Violette. Hydraulic and chemical pulse tests in a shut-in chamber imbedded in an argillaceous formation: Numerical and experimental approaches. Water Resources Research, 2010, 46 (8), pp.n/a - n/a. 10.1029/2008WR007371 . hal01501989

\author{
HAL Id: hal-01501989 \\ https://hal.science/hal-01501989
}

Submitted on 31 Oct 2021

HAL is a multi-disciplinary open access archive for the deposit and dissemination of scientific research documents, whether they are published or not. The documents may come from teaching and research institutions in France or abroad, or from public or private research centers.
L'archive ouverte pluridisciplinaire HAL, est destinée au dépôt et à la diffusion de documents scientifiques de niveau recherche, publiés ou non, émanant des établissements d'enseignement et de recherche français ou étrangers, des laboratoires publics ou privés. 


\section{Hydraulic and chemical pulse tests in a shut-in chamber imbedded in an argillaceous formation: Numerical and experimental approaches}

P. Rousseau-Gueutin, ${ }^{1,2,3}$ J. Gonçalvès, ${ }^{1}$ M. Cruchaudet, ${ }^{4}$ G. de Marsily, ${ }^{1}$ and S. Violette ${ }^{1}$ Received 19 August 2008; revised 21 December 2009; accepted 12 January 2010; published 7 August 2010.

[1] Hydraulic and chemical pulse tests were performed in four shut-in chambers to obtain hydraulic and chemical parameters of the Callovo-Oxfordian shale. The osmotic tests, i.e., chemical pulses, were carried out by exchange of the formation water for a different solution either more or less concentrated. Two sets of two osmotic tests were done in March and October 2006. These osmotic tests are superimposed on a purely hydraulic response because of the drilling of the well causing a pressure drop. The pressure records (hydraulic and osmotic responses) were interpreted using a 2-D model to obtain the hydraulic and chemical parameters. The osmotic efficiency inferred for the Callovo-Oxfordian shale is on the order of 0.012 for a concentration of $0.43 \mathrm{~mol} \mathrm{~L}^{-1}$ and 0.12 for a concentration of $0.086 \mathrm{~mol} \mathrm{~L}^{-1}$. These results suggest that the Callovo-Oxfordian shale behaves as a weakly semipermeable membrane and only $0.1-0.15 \mathrm{MPa}$ of the $0.2-0.5 \mathrm{MPa}$ can be explained by these osmotic efficiency values.

Citation: Rousseau-Gueutin, P., J. Gonçalvès, M. Cruchaudet, G. de Marsily, and S. Violette (2010), Hydraulic and chemical pulse tests in a shut-in chamber imbedded in an argillaceous formation: Numerical and experimental approaches, Water Resour. Res., 46, W08516, doi:10.1029/2008WR007371.

\section{Introduction}

[2] The great importance of understanding fluid and solute flows in weakly permeable media such as shale layers is underlined in a large number of studies dealing with, e.g., contaminant transport [Keijzer et al., 1999; Malusis and Shackelford, 2002a] or pressure fields in sedimentary basins [Fritz and Marine, 1983; Marine and Fritz, 1981; Fritz, 1986; Neuzil, 1995]. The first question that arises when dealing with transport in such media is what are the relevant transport processes? In argillaceous formations, Neuzil [2000] has clearly established the possible occurrence of chemical osmosis, i.e., a fluid flow driven by a salinity gradient. This osmotic term is due to the membrane properties attributed to shale layers, which has made it more complicated to identify transport properties in such media. In fact, argillaceous low-permeability media are often studied because of their behavior as semipermeable membranes [e.g., Kemper and Rollins, 1966; Olsen, 1969; Horseman et al., 1996; Neuzil, 2000]. Semipermeability is defined as the capacity of a membrane to completely or partially prevent ionic transfer without affecting that of neutral species, for example, water [Mitchell, 1993; Neuzil and Provost, 2009]. In clay media, this capacity is due to the existence of an

\footnotetext{
${ }^{1}$ Sisyphe, UMR 7619, Université Pierre et Marie Curie, CNRS, Paris, France.

${ }^{2}$ ANDRA, Châtenay-Malabry, France.

${ }^{3}$ Now at School of the Environment, Flinders University, Adelaide, South Australia, Australia.

${ }^{4}$ ANDRA, Bure, France.

Copyright 2010 by the American Geophysical Union. 0043-1397/10/2008WR007371
}

electrical double layer at the clay surface [Bolt, 1979; Mitchell, 1993].

[3] The membrane behavior of weakly permeable media is associated with the existence of the so-called coupled fluxes, e.g., of water and solute [Katchalsky and Curran, 1967; Bolt, 1979; Neuzil, 1986; Revil, 1999; Moyne and Murad, 2002]. For instance, in this type of media, the fluid flow is no longer the result of Darcy's flow alone [Neuzil, 1986; de Marsily, 1986; Revil and Pessel, 2002]. Coupled flows are flows of water, solute, electric current, and heat that share the same driving forces, i.e., the gradients of pressure, chemical potential, electrical potential, and temperature [Bolt, 1979; Mitchell, 1993; Horseman et al., 1996]. Consequently, the flows are interdependent and must be calculated together, whence the notion of coupling.

[4] Chemical osmosis, for instance, is the water flow caused by a chemical-potential difference in the water on either side of a semipermeable membrane (e.g., clay) [Katchalsky and Curran, 1967; Mitchell, 1993; Horseman et al., 1996]. The flow direction is that of diminishing chemical potential in the water. Chemical osmosis is thought to be the main coupled flow and is thus the subject of numerous studies dealing with argillaceous media [e.g., Kemper and Quirk, 1972; Keijzer et al., 1999; Neuzil, 2000; Malusis and Shackelford, 2002a; Gonçalvès et al., 2004, 2007; Gonçalvès, 2008; Rousseau-Gueutin et al., 2008, 2009]. Some studies deal more specifically with estimates of the chemical osmosis coupling coefficient. This osmotic coupling coefficient represents the capacity of the membrane to behave as a semipermeable boundary. It is often described with the help of the so-called dimensionless osmotic efficiency or reflection coefficient [Mitchell, 1993; Horseman et al., 1996; Neuzil, 2000], which varies between 0 and 1. A zero value signifies that the medium has no membrane 


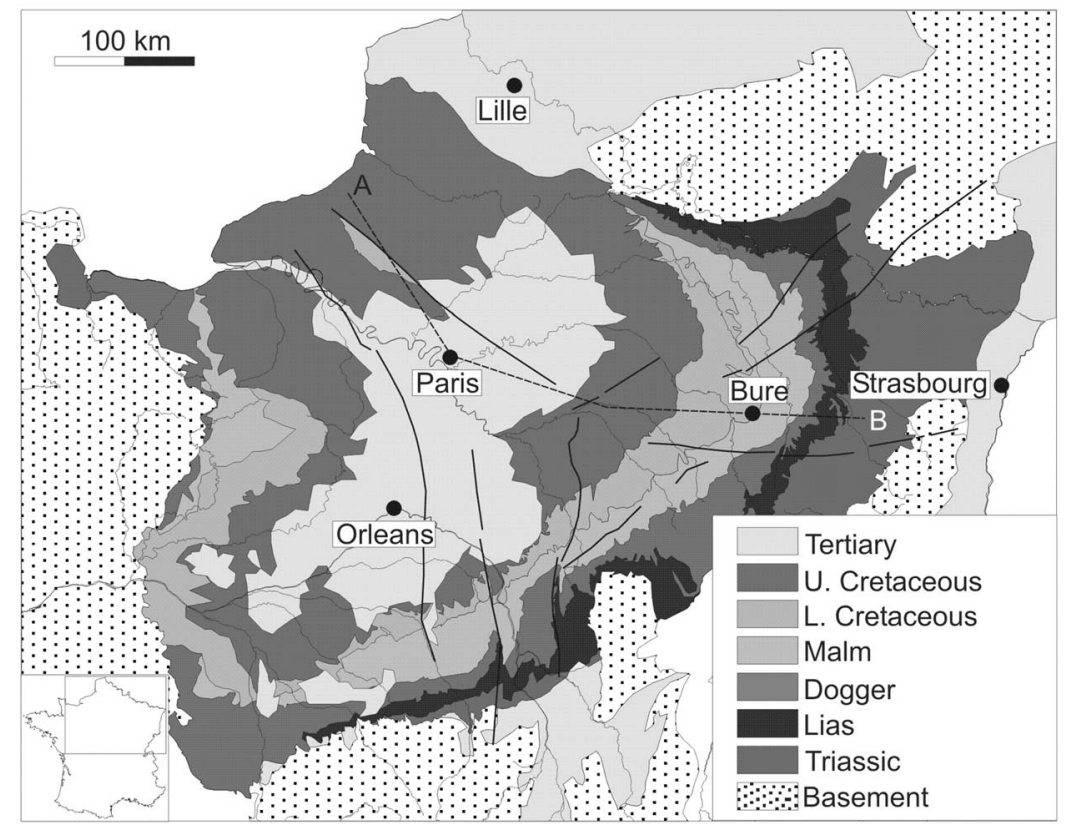

Figure 1. Location of the Bure site $\left(2^{\circ} \mathrm{W}-8^{\circ} \mathrm{E}\right.$ longitude, $46^{\circ} \mathrm{N}-51^{\circ} \mathrm{N}$ latitude [from Gonçalvès et al., 2004].

characteristics; that is, the ionic transport is unchanged. Conversely, a value of 1 indicates a perfect membrane through which there is no ionic transport.

[5] From the 1960s, many experiments have been performed to characterize osmotic processes in clay-rocks at the sample scale and at the field scale. A large number of samplescale experiments have been performed on different pure materials: smectite, bentonite, illite, kaolinite, and, more rarely, on natural materials [Kemper and Rollins, 1966; Kemper and Quirk, 1972; Keijzer, 2000; Cey et al., 2001; Malusis and Shackelford, 2002a; Horseman et al., 2007; Rousseau-Gueutin et al., 2009]. Few experiments have been performed at the field scale [Neuzil, 2000; Noy et al., 2004; Garavito et al., 2007; Cruchaudet et al., 2008].

[6] Argillaceous media are increasingly studied, especially for their confining properties. Obviously, any quantitative effort to characterize transport processes in such media requires some reliable values for their transport parameters. The Callovo-Oxfordian at the Bure site is the clay formation studied to evaluate the feasibility of deep radioactive waste disposal in France. An osmotic process has been invoked in a previous study to explain the overpressures measured in the formation $(0.2-0.5 \mathrm{MPa})$, as compared to the surrounding aquifers [Gonçalvès et al., 2004]. In this previous study, the authors commented on the necessity for an experimental estimate of the osmotic efficiency to arrive at concrete conclusions. In shale layers, a very efficient method to obtain such values is the slug test in shut-in wells. During this test, an initial hydraulic or chemical pulse is imposed in an isolated chamber drilled in a shale formation. These pulses consist of an instantaneous variation of the pressure (hydraulic test) or the salinity (osmotic test) imposed in the chamber. The subsequent pressure response of the fluid located in this chamber is recorded. In this context, four osmotic tests (chemical pulses) have been performed by the French National Agency for Radioactive Waste Management (ANDRA) in the under- ground research laboratory at Bure (Figure 1). These tests must be interpreted by means of analytical or numerical solutions.

[7] Different models have been developed for the interpretation of chemical pulses [Noy et al., 2004; Bader and Kooi, 2005; Garavito et al., 2007]. However, the physical properties of the measurement chamber have not been distinctly accounted for in these studies. For instance, Garavito et al. [2007] considered the chamber as a porous medium with a high intrinsic permeability. This model, which does not introduce any hydraulic specificity of the chamber, was used in a previous exploratory study to interpret the osmotic data set for the Callovo-Oxfordian [Cruchaudet et al., 2008]. In this study, our purpose is to reinterpret these four in situ osmotic experiments with a new numerical model, which individualizes and characterizes the porous medium and the measurement chamber by distinct sets of equations, and the measured overpressures in the Callovo-Oxfordian with the osmotic efficiency inferred in this study.

\section{Experimental Setting and Data}

\subsection{Characterization of the Callovo-Oxfordian Formation}

[8] The Bure site (eastern part of the Paris basin, Figure 1) has been chosen for a feasibility study of a radioactive waste repository in the low-permeability layer of the CallovoOxfordian (Figure 2) at a depth of around $500 \mathrm{~m}$. The Callovo-Oxfordian is a consolidated argillaceous rock, about $120 \mathrm{~m}$ thick. Research has been carried out continuously since 1993 to characterize this rock geologically, hydrogeologically, and chemically (Table 1). The Callovo-Oxfordian formation is composed of clay minerals (illite-smectite), carbonates, and secondary minerals [Gaucher et al., 2004].

[9] A chemical analysis of the pore water shows a complex composition of the interstitial water with a salinity of $5 \mathrm{~g} \mathrm{~L}^{-1}$ 


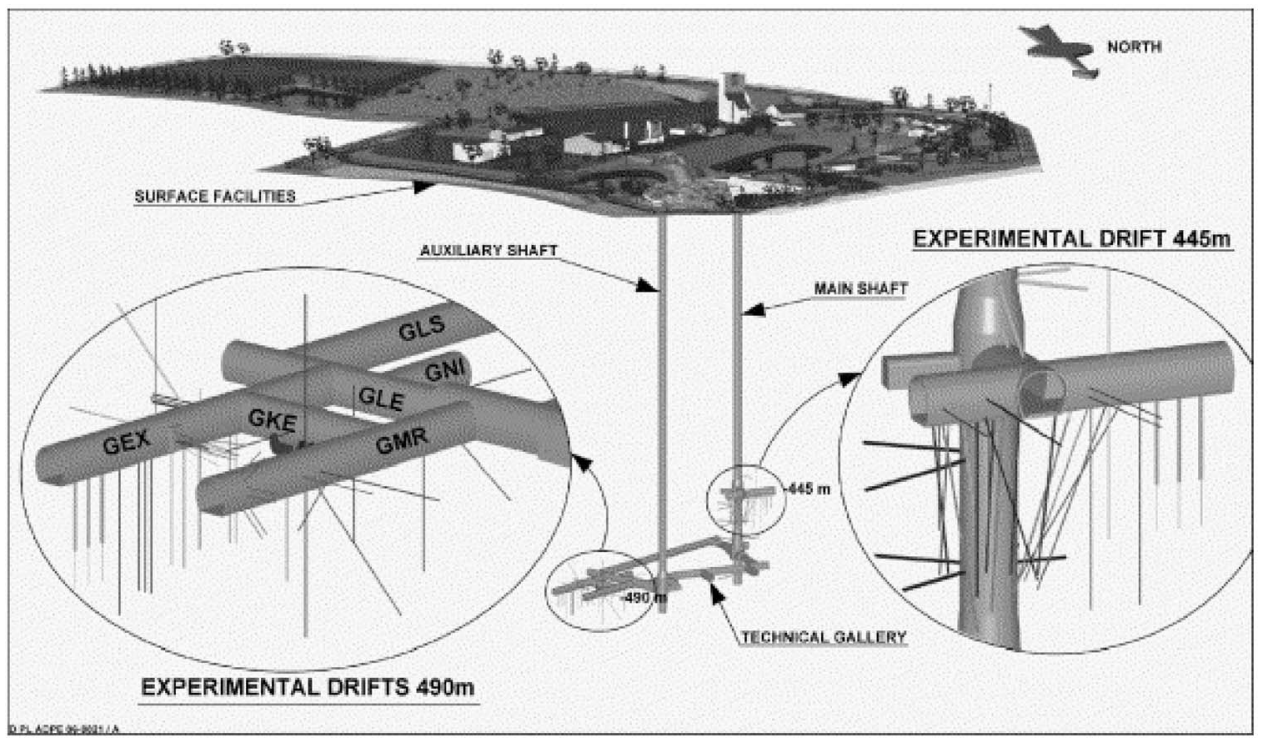

Figure 2. General view of the underground laboratory at Bure [from Delay et al., 2007].

(total dissolved salts) [Delay et al., 2006]. The effective diffusion coefficient estimated on samples and in situ is on the order of $2.5 \times 10^{-11} \mathrm{~m}^{2} \mathrm{~s}^{-1}$ for tritiated water (HTO) and $5 \times$ $10^{-12} \mathrm{~m}^{2} \mathrm{~s}^{-1}$ for anions [Agence Nationale Pour la Gestion des Déchets Radioactifs (ANDRA), 2005; Descostes et al., 2008 ] with an anisotropy ratio (horizontal to vertical) which ranges from 2 to 6 [García-Gutiérreza et al., 2008]. Because of the anionic exclusion [Melkior et al., 2007] and the electroneutrality, the cations are transported with the anions. Therefore, the anion diffusion coefficient is theoretically representative of that of the cations.

[10] Several types of hydrogeological characterizations were carried out. The permeability was determined by means of several test types (e.g., slug test, electromagnetic pressure gauge) [Distinguin and Lavanchy, 2007]. The range of measured horizontal permeability lies between $9 \times 10^{-22}$ and $1 \times 10^{-19} \mathrm{~m}^{2}$ with an anisotropy ratio which ranges from 1.5 to 3 [Delay et al., 2006; Homand et al., 2006]. Several methods were used to estimate the total porosity (e.g., mercury or oil) of 15\% [Gaucher et al., 2004]. The compressibilities of the measurement chambers used in the experiments were experimentally estimated to be on the order of $1.02 \times$ $10^{-9}$ to $1.80 \times 10^{-9} \mathrm{~Pa}^{-1}$ [Cruchaudet et al., 2008].

[11] Two previous studies have estimated the osmotic efficiency of the Callovo-Oxfordian. Cruchaudet et al. [2008] inferred osmotic values from the interpretation of the same in situ measurements as those used in this study. They found that the osmotic efficiency ranges between 0.05

Table 1. Parameters from Modeling Experiments on the Callovo-Oxfordian Formation

\begin{tabular}{|c|c|c|c|c|}
\hline Symbol & Parameter & Minimum Value & Maximum Value & Value \\
\hline$k^{\mathrm{a}}$ & intrinsic permeability $\left(\mathrm{m}^{2}\right)$ & $9 \times 10^{-22}$ & $1 \times 10^{-19}$ & \\
\hline$a_{z}^{\mathrm{b}, \mathrm{c}}$ & anisotropy ratio & 1.5 & 3 & \\
\hline$S_{S}^{\mathrm{b}}$ & specific storage coefficient $\left(\mathrm{m}^{-1}\right)$ & $10^{-7}$ & $10^{-4}$ & \\
\hline$\beta_{c}$ & chamber compressibility $\left(\mathrm{Pa}^{-1}\right)$ & $7 \times 10^{-10}$ & $2 \times 10^{-9}$ & \\
\hline$\omega^{\mathrm{d}}$ & porosity & 0.02 & 0.22 & \\
\hline$b^{\mathrm{e}}$ & half pore size & $3 \AA$ & $10 \mu \mathrm{m}$ & \\
\hline$D_{\text {НTO }}{ }^{\mathrm{f}}$ & diffusion coefficient & & & \\
\hline & tritiated water $\left(\mathrm{m}^{2} \mathrm{~s}^{-1}\right)$ & $1.4 \times 10^{-11}$ & $4.9 \times 10^{-11}$ & \\
\hline$D_{\text {anions }}{ }^{t}$ & $\begin{array}{l}\text { diffusion coefficient } \\
\text { anionic species }\left(\mathrm{m}^{2} \mathrm{~s}^{-1}\right)\end{array}$ & $5 \times 10^{-13}$ & $7 \times 10^{-12}$ & \\
\hline $\mathrm{C}_{\mathrm{Na}+}{ }^{\mathrm{g}}$ & concentration of $\mathrm{Na}^{+}\left(\mathrm{mol} \mathrm{L}^{-1}\right)$ & & & $2.77 \times 10^{-2}$ \\
\hline $\mathrm{C}_{\mathrm{K}+}^{\mathrm{g}}$ & concentration of $\mathrm{K}^{+}\left(\mathrm{mol} \mathrm{L}^{-1}\right)$ & & & $6.82 \times 10^{-3}$ \\
\hline $\mathrm{C}_{\mathrm{Mg}^{2+}}^{\mathrm{g}}$ & concentration of $\mathrm{Mg}^{2+}\left(\mathrm{mol} \mathrm{L}^{-1}\right)$ & & & $1.00 \times 10^{-2}$ \\
\hline $\mathrm{C}_{\mathrm{Ca}^{2+}} \mathrm{g}$ & concentration of $\mathrm{Ca}^{2+}\left(\mathrm{mol} \mathrm{L}^{-1}\right)$ & & & $1.33 \times 10^{-2}$ \\
\hline $\mathrm{C}_{\mathrm{Sr}^{2+}} \mathrm{g}$ & concentration of $\mathrm{Sr}^{2+}\left(\mathrm{mol} \mathrm{L}^{-1}\right)$ & & & $1.00 \times 10^{-4}$ \\
\hline $\mathrm{C}_{\mathrm{Cl}^{-}}{ }^{\mathrm{g}}$ & concentration of $\mathrm{Cl}^{-}\left(\mathrm{mol} \mathrm{L}^{-1}\right)$ & & & $3.03 \times 10^{-2}$ \\
\hline $\mathrm{C}_{\mathrm{SO}_{4}^{2-}}{ }^{\mathrm{g}}$ & concentration of $\mathrm{SO}_{4}^{2-}\left(\mathrm{mol} \mathrm{L}^{-1}\right)$ & & & $2.50 \times 10^{-2}$ \\
\hline
\end{tabular}

\footnotetext{
${ }^{\mathrm{a}}$ Distinguin and Lavanchy [2007].

${ }^{\mathrm{b}}$ Delay et al. [2006].

${ }^{\mathrm{c}}$ Homand et al. [2006].

${ }^{\mathrm{d}}$ Gaucher et al. [2004].

${ }^{\mathrm{e}}$ Leroy et al. [2007].

${ }^{\mathrm{f}}$ Descostes et al. [2008].

${ }^{\mathrm{g}}$ Cruchaudet et al. [2008].
} 


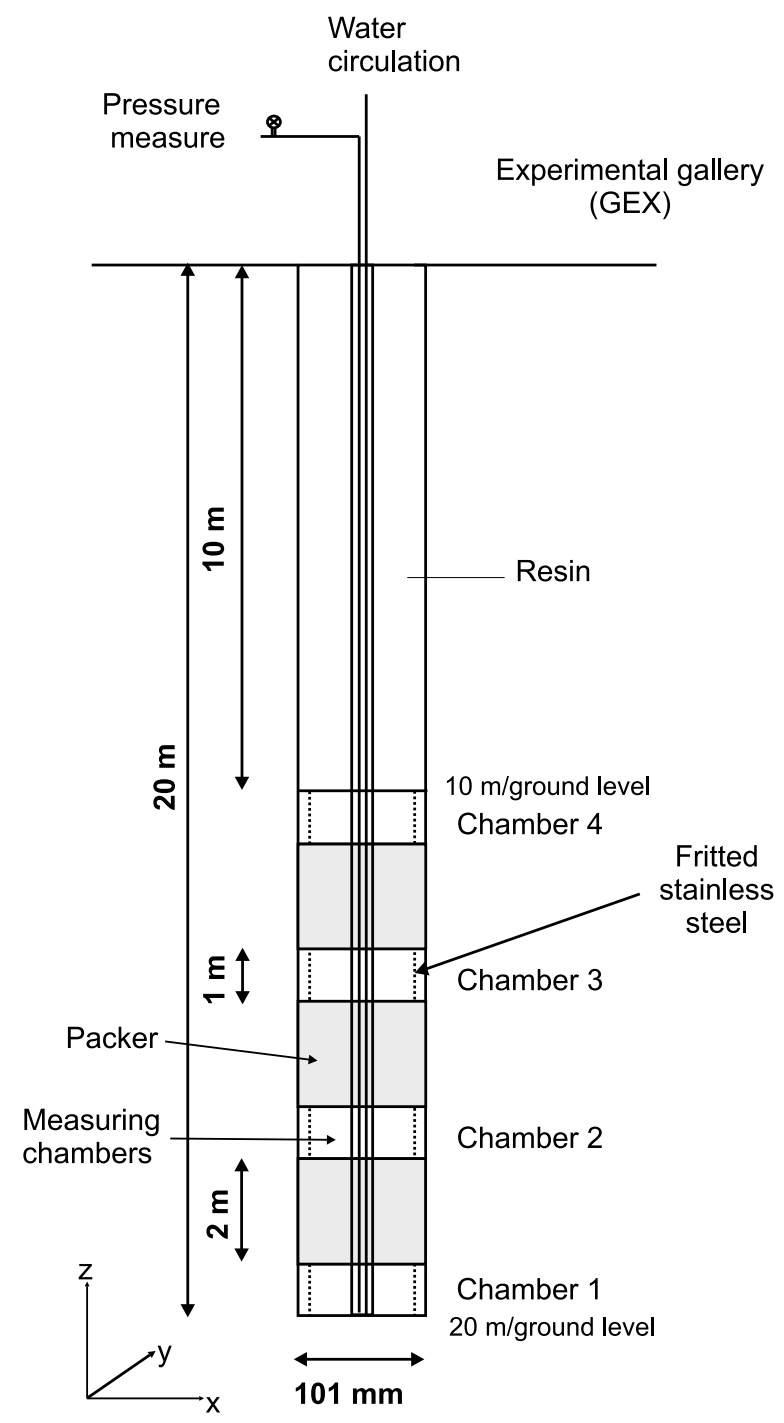

Figure 3. Schematic sketch of the PEP1001 well, purposebuilt for the osmotic experiments in the underground laboratory (not drawn to scale).

and 0.18 for a concentration of $0.086 \mathrm{~mol} \mathrm{~L}^{-1}$. They obtained these values by the interpretation of the data in only two chambers (chambers 2 and 4; see section 2.2). To interpret these data, they used the model developed by Garavito et al. [2007], in which the measurement chamber is considered as a high-permeability zone. In this previous work, Cruchaudet et al. [2008] interpreted only two out of the four osmotic pulse tests. Rousseau-Gueutin et al. [2009] inferred osmotic efficiency from sample-scale experiments. In their study they found that the osmotic efficiency ranges between 0.015 and 0.28 for concentrations of $0.6 \mathrm{~mol} \mathrm{~L}^{-1}$ and $0.094 \mathrm{~mol} \mathrm{~L}^{-1}$, respectively.

\subsection{Experimental Protocol}

[12] The experimental setup is only briefly presented here; more details can be found in work by Cruchaudet et al. [2008]. The borehole was drilled vertically downward, from the multiexperiment gallery in the underground research laboratory $(-490 \mathrm{~m})$, to a depth of $20 \mathrm{~m}$ (Figures 2 and 3). It was equipped with a multipacker to create four separate measurement chambers [Cruchaudet et al., 2008]. A fritted stainless steel screen with a $30 \%$ porosity was added on the outside of the chambers to prevent total closure of the chambers by creeping.

[13] The drilling technique causes a decompression and a local desaturation around the borehole [Matray et al., 2007] and creates a hydraulic slug. The drilling was completed on 11 November 2005, and on 14 November the chambers were refilled with synthetic water at a concentration of $5 \mathrm{~g} \mathrm{~L}^{-1}$ (the formation fluid composition is given in Table 1), after which the pressures in the chambers started to rise to recover the formation pressure. This phase lasts until a potential pressure stabilization. The objective of osmotic tests is to modify the composition of the water in a shut-in chamber in a borehole and to measure the effects of this chemical pulse on the chamber pressure [Neuzil, 2000; Noy et al., 2004; Garavito et al., 2007]. On 15 and 16 March 2006, when the stabilization of the pressure was judged sufficient (less than $15 \mathrm{kPa}$ per 15 days variation), two tests were made: on 15 March, the initial solution of chamber 1 was replaced by a solution with a salinity of $1 \mathrm{~g} \mathrm{~L}^{-1}$. On 16 March 2006, the solution in chamber 3 was replaced by one with a salinity of $7 \mathrm{~g} \mathrm{~L}^{-1}$. In this first test set, chambers 2 and 4 were used as control chambers; that is, their salinity remained unchanged. A second set of osmotic tests started on 25 and 26 October 2006. On 25 October the water in chamber 2 was replaced by a solution with a salinity of $25 \mathrm{~g} \mathrm{~L}^{-1}$. On 26 October, the water in chamber 4 was replaced by a solution with a salinity of $100 \mathrm{~g} \mathrm{~L}^{-1}$. During this phase, the concentration in chamber 3 remained unchanged, while the water in chamber 1 was replaced by the formation solution and can be considered unchanged. Chambers 1 and 3 can be considered as controls. The salinities used for the osmotic tests were chosen from predictive simulations performed with the OSMO1R model [Noy et al., 2004; Cruchaudet et al., 2008]. The chemical pulses were conducted with solutions modified (by addition of $\mathrm{NaCl}$ or dilution) from the theoretical pore solution of the Callovo-Oxfordian (Table 1).

\subsection{Pressure Records}

[14] The time series starts after the filling of the chambers with the initial solution on 14 November 2005 (Figure 4). The pressure recovery, after the initial hydraulic slug (drilling of the borehole), represents the major signal of the pressure records. The pressures started to stabilize in the chambers after around 2 months (Figure 4) with values on the order of $4 \mathrm{MPa}$.

[15] Although weak, a perturbation by the underground laboratory galleries is evident from the pressure records which show slow pressure decreases. This pressure perturbation could result from a hydromechanical coupling effect which affects the pressure in the porous medium around the gallery just after its drilling (see section 3.2). This effect can be identified on the pressure signals only when it becomes significant compared to the pressure recovery signal. This effect is visible at first in chamber 4 , which is the closest one from the gallery $(10.5 \mathrm{~m})$. It was difficult to identify it in chamber 2 because it was overlaid by the response to the chemical pulse. The osmotic tests (15-16 March 2006 and 25-26 October 2006) are shown in Figure 4. The effects of 


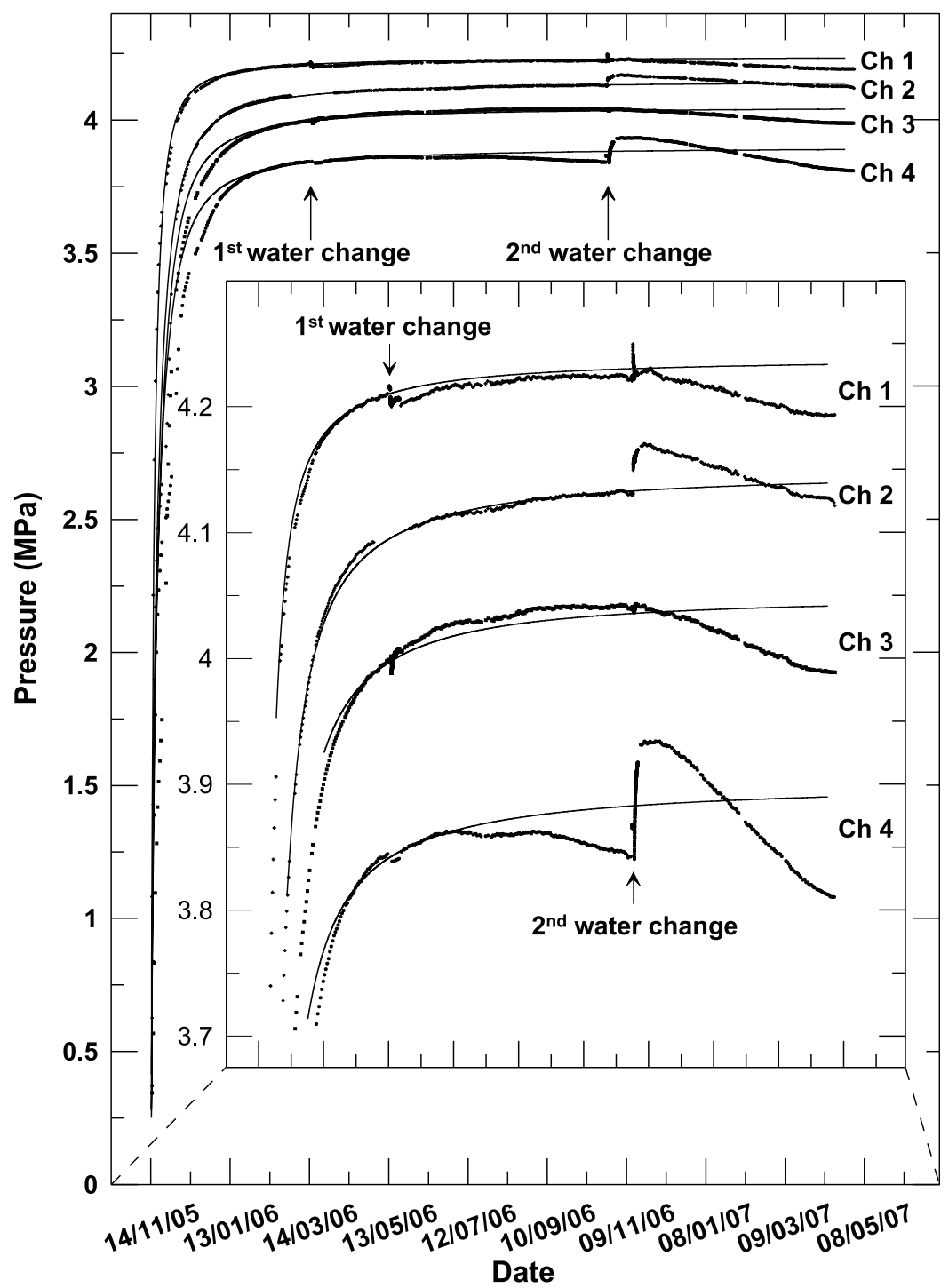

Figure 4. Measured (dots) and simulated (purely hydraulic model, solid line) pressures in the four shut-in chambers.

these chemical perturbations are more or less visible on the curves.

[16] Figure 4 illustrates two major challenges in the interpretation of the osmotic experiments. In the first set of tests, the osmotic effects are not very visible on the curves; to interpret them, it is necessary to carry out a very precise simulation of the purely hydraulic pressure recovery. On the other hand, the effects of the second set of tests are easily discernable, but the perturbation due to the galleries affects the pressures with a pressure trend (no stabilized pressures). To interpret the second set, it is therefore necessary to take into account the trend. The model presented in section 3 was developed with these two objectives.

\section{Modeling in Situ Chemo-osmotic Pulse Tests}

\subsection{A Short Theoretical Background}

[17] Assuming isothermal condition with a zero net macroscopic current density, the coupled flow and transport equations to describe the process are [Katchalsky and Curran,
1967; Bolt, 1979; Soler, 2001; Malusis and Shackelford, 2002a; Revil and Leroy, 2004; Bader and Kooi, 2005]

$$
\begin{gathered}
q=-\frac{k}{\eta}\left(\nabla p+\rho_{f} g \nabla z\right)+\frac{k_{c}}{\eta} \nabla \Pi \\
J_{d}=-\omega D_{p} \nabla c+(1-\varepsilon) c q,
\end{gathered}
$$

where $q$ is the specific discharge $\left(\mathrm{m} \mathrm{s}^{-1}\right), k$ is the intrinsic permeability $\left(\mathrm{m}^{2}\right), \eta$ is the dynamic viscosity of the water ( $\mathrm{Pa} \mathrm{s}), p$ is the pressure $(\mathrm{Pa}), \rho_{f}$ is the density of the water $\left(\mathrm{kg} \mathrm{m}^{-3}\right), g$ is the acceleration due to gravity $\left(\mathrm{m} \mathrm{s}^{-2}\right), z$ is the elevation $(\mathrm{m}), J_{d}$ is the solute flux per unit surface of porous medium (mol m $\mathrm{m}^{-2}$ ), $k_{c}$ is the osmotic permeability $\left(\mathrm{m}^{2}\right)$, $\omega$ is the porosity, $D_{p}$ is the diffusion coefficient in the porous medium $\left(\mathrm{m}^{2} \mathrm{~s}^{-1}\right)$ (the effective diffusion coefficient is defined as $\left.D_{\text {eff }}=\omega D_{p}\right), \varepsilon$ is the nondimensional osmotic efficiency, and $c$ is the concentration $\left(\mathrm{mol} \mathrm{L}^{-1}\right)$. The solute transport formalism indicates that kinematic dispersion is not taken into account. Most authors define osmotic efficiency 


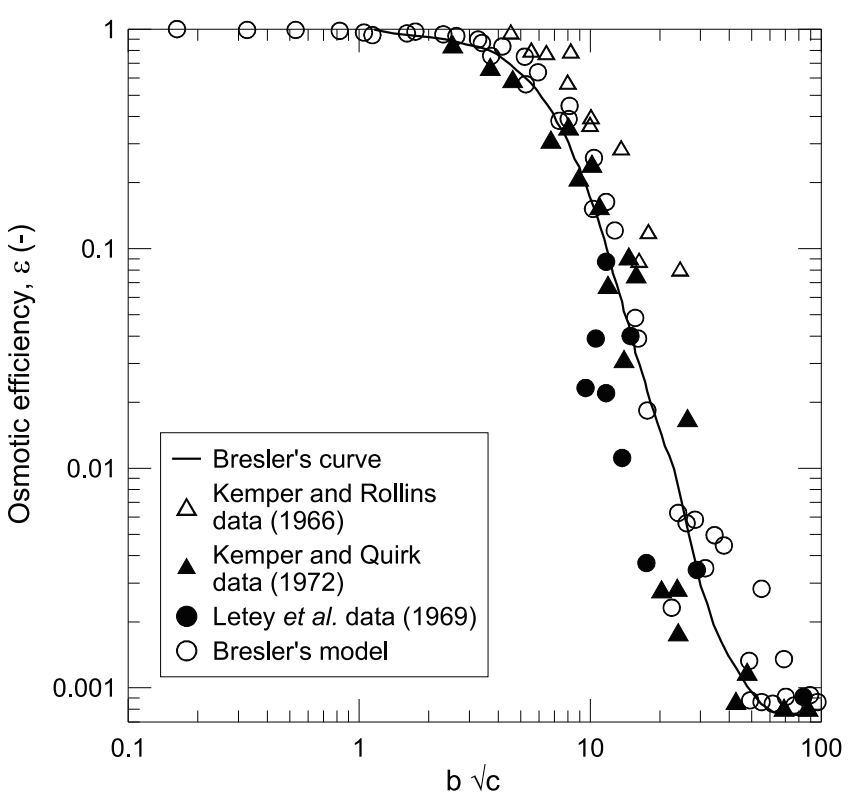

Figure 5. Relation between the osmotic efficiency coefficient and the product of concentration $\left(c\right.$, in mol L $\left.{ }^{-1}\right)$ and half-pore size ( $b$, in $\AA$ ) [from Bresler, 1973].

as dependent on the concentration $\varepsilon=\varepsilon(c)=\left(k_{c}\right) /(k)$ [see, e.g., Staverman, 1952; Katchalsky and Curran, 1967]. The term $(1-\varepsilon) C q$ describes the advective solute flux [Katchalsky and Curran, 1967; Malusis and Shackelford, 2002b].

[18] According to equation (2), if $\varepsilon=1$ (perfect membrane), the advective term is zero. In addition, in this case, $D_{\text {eff }}$ is very weak, yielding a zero solute transport [Revil and Leroy, 2004; Revil et al., 2005, Figure 14]. Indeed, there is a relation between the coefficient of osmotic coupling and that of effective diffusion [Katchalsky and Curran, 1967; Manassero and Dominijanni, 2003; Bader and Kooi, 2005; Malusis and Shackelford, 2004; Revil et al., 2005]. Theoretically, when the membrane is perfect $(\varepsilon=1)$, the effective ionic diffusive flux is zero $\left(D_{\text {eff }} \approx 0\right)$. Thus, when the osmotic coupling coefficient is large (close to 1), the effective diffusion coefficient is small, and ionic transport is greatly reduced.

[19] With the system of equations (1) and (2) one can interpret the chemical osmosis experiments during which a concentration gradient, and thus a chemical potential gradient, is imposed across a medium. Chemical osmosis is defined as the movement of water through a semipermeable membrane due to the gradient of chemical potential in the water. Therefore, a difference in concentration on either side of a semipermeable membrane causes a movement of the water from the solution with the highest chemical potential in the water (the weakest concentration) toward the solution with the lowest chemical potential (the highest concentration). Thus, a concentration difference induces a more or less permanent pressure perturbation.

[20] The osmotic pressure can be approximated by van 't Hoff's law:

$$
\Pi=\nu R T C,
$$

where $\Pi$ is the osmotic pressure $(\mathrm{Pa}), \nu$ is the number of ions dissociated from the salt (e.g., 2 for $\mathrm{NaCl}$ ), $R$ is the gas constant $\left(8.32 \times 10^{3} \mathrm{~m}^{3} \mathrm{~Pa} \mathrm{~K}^{-1} \mathrm{~mol}^{-1}\right), T$ is the absolute temperature $(\mathrm{K})$, and $C$ is the salt concentration $\left(\mathrm{mol} \mathrm{L} \mathrm{L}^{-1}\right.$ ). This equation holds for an ideal solution, i.e., a solution with a concentration of less than $1 \mathrm{~mol} \mathrm{~L}^{-1}$ [Fritz, 1986].

[21] Classically, in the case of two reservoirs separated by a perfect membrane (no possible ionic transport), after some equilibration time, a permanent pressure difference is established between the two reservoirs. For ideal solutions,

$$
\Delta p=\Delta \Pi=\nu R T \Delta C
$$

[22] Geologic media generally behave as imperfect semipermeable membranes; that is, ion transport is not entirely excluded. Equations (1) and (2) describe this behavior $(\varepsilon \neq 1)$. With the osmotic coupling coefficient it is possible to estimate the membrane capacity of a semipermeable medium. It is defined at a singular point for zero water velocity, i.e., $q=0$ [Staverman, 1952; Katchalsky and Curran, 1967; Neuzil, 2000; Revil et al., 2005]. Equation (1), by neglecting the gravity driven flow, becomes

$$
\varepsilon=\frac{k_{c}}{k}=\left.\frac{\Delta p}{\Delta \Pi}\right|_{q=0},
$$

where $\varepsilon$ is the osmotic efficiency, $k_{c}$ is the osmotic permeability $\left(\mathrm{m}^{2}\right), k$ is the intrinsic permeability $\left(\mathrm{m}^{2}\right)$, and $\Delta p$ and $\Delta \Pi$ are the maximum pressure difference measured on either side of a membrane during an osmotic process and the theoretical osmotic pressure difference calculated with van 't Hoff's equation (equation (3)), respectively.

[23] Several models were developed to estimate the osmotic efficiency. The widely used model is Bresler's curve [Bresler, 1973], which provides the osmotic efficiency as a function of the concentration and the pore size (Figure 5). This curve, widely used to predict the osmotic efficiency, represents the best fit on simulated results. The error between this fit and the data can be considerable. For instance, for a value of 20.5 for $b \sqrt{c}$, the data obtained by Kemper and Rollins [1966] is 0.07, whereas Bresler's curve gives a value of 0.01 .

\subsection{Numerical Model}

[24] Here a numerical model was developed for the very special geometry of a shut-in well within a geological formation (Figure 6). The measurement chamber makes it necessary to introduce a special set of equations in addition to those required for the porous medium (equations (1) and (2)). It has to be noted here that chemical compaction has not been taken into account. In order to prevent any deformation of the chamber wall, a fritted stainless steel screen was placed into the borehole during the installation.

[25] By combining the continuity equation for horizontal and $2-\mathrm{D}$ flow in a finite volume of porous medium and equation (1), in which the gravity effects are neglected, one obtains the pressure diffusion equation with a source term $Q$ [de Marsily, 1986]:

$$
\operatorname{div}\left[\rho_{f}\left(-\frac{k}{\eta} \nabla p+\varepsilon \frac{k}{\eta} \nabla \Pi\right)\right]=-\frac{S_{s}}{g} \frac{\partial p}{\partial t}+\rho_{f} Q,
$$

where $\rho_{f}$ is the density of the water $\left(\mathrm{kg} \mathrm{m}^{-3}\right) ; k$ is the intrinsic permeability $\left(\mathrm{m}^{2}\right) ; \eta$ is the dynamic viscosity of the water $(\mathrm{Pa} \mathrm{s}) ; p$ is the pressure in the porous medium $(\mathrm{Pa}) ; \varepsilon$ is the 

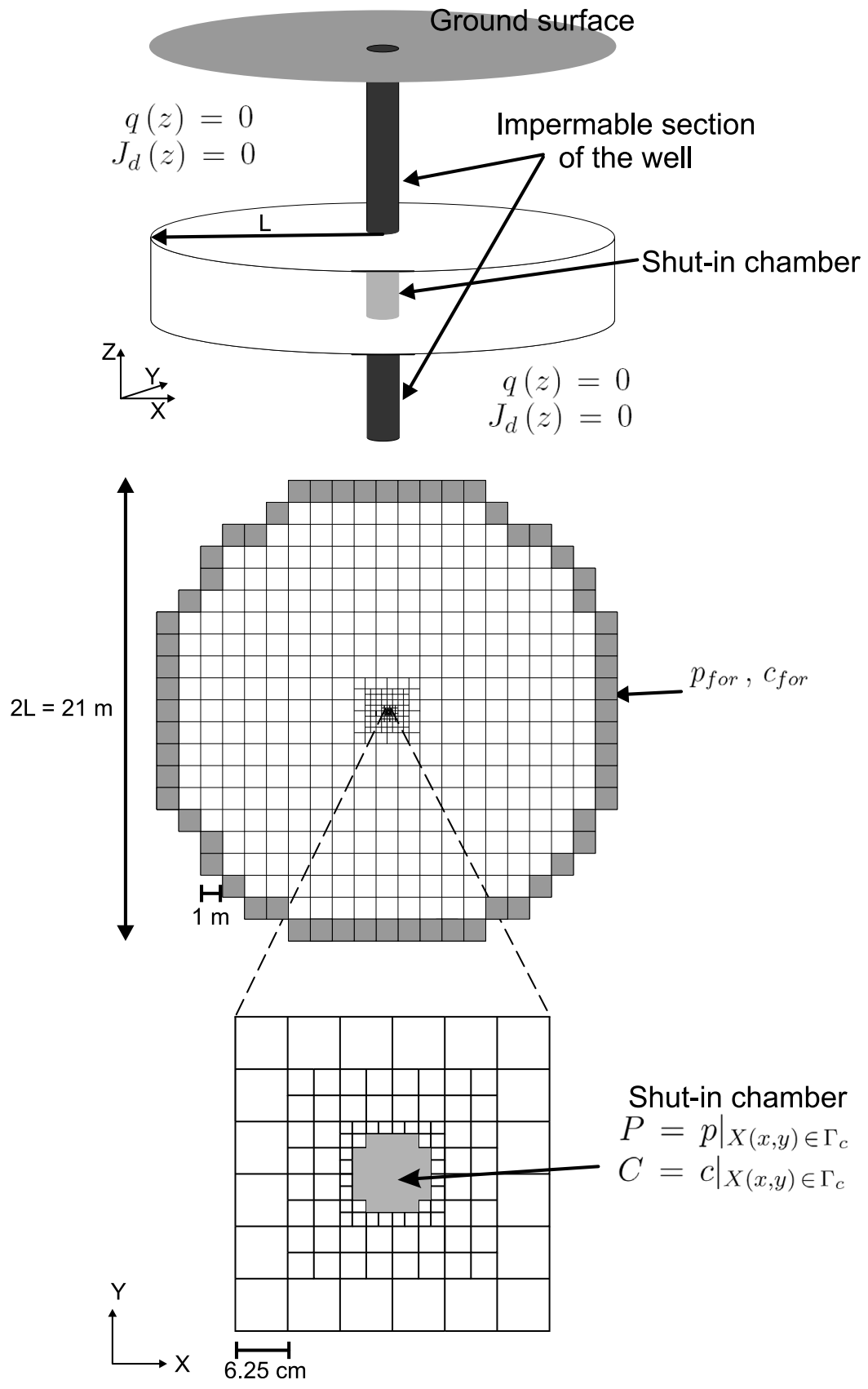

Figure 6. Geometry, dimensions, and boundary conditions of the modeled domain.

osmotic efficiency coefficient, depending on the concentration; $\Pi$ is the osmotic pressure $(\mathrm{Pa}) ; S_{S}$ is the specific storage coefficient $\left(\mathrm{m}^{-1}\right) ; g$ is the acceleration due to gravity $\left(\mathrm{m} \mathrm{s}^{-2}\right)$; $t$ is the time (s); and $Q$ is the source term $\left(\mathrm{s}^{-1}\right)$.

[26] As previously noted, the pressures in the chambers have been disturbed by the gallery network. The perturbation due to the galleries, a decreasing trend, is complex to simulate and would require $3-\mathrm{D}$ modeling to account for the timedependent gallery drilling effect. The pore pressure changes caused by gallery excavation in indurated clays such as the Callovo-Oxfordian formation are controlled by two processes [Tsang et al., 2008]: (1) the pore pressure will increase because of the undrained compression of the rock caused by excavation, and (2) the drainage of the water toward the gallery leads to a cone of depression and thus a pore pressure decrease. Therefore, the perturbation identified here results from a complex hydromechanical coupling which is strongly dependent on the mechanical properties of the rocks. From a theoretical standpoint, the hydromechanical effect could be accounted for using a distributed and time variable source term of the form $Q=S s / \rho_{f} g \times \partial \sigma / \partial t$, where $\partial \sigma / \partial t$ is the evolution in time of the total stress [Neuzil, 1995; Gonçalvès et al., 2004].

[27] A theoretical calculation of the source term $Q$ using a mechanical formulation would be speculative because of the uncertainties on the mechanical parameters. We chose instead an empirical approach, which was to calibrate a single, timevariable point source $Q$ for each measurement chamber, representing both effects. This single-source term is assumed uniform and is assigned to each node of the model, and its 
time-varying magnitude was calibrated using the reference chambers pressure records. If properly calibrated, this adequately represents the behavior at the reference chambers (see part 4.2), and, since the measurement chambers are very close to the reference chambers, it is a good approximation of what would have been measured in these chambers without the prescribed perturbations. This gallery effect was added to verify the ability of the model to capture the purely osmotic signal and to identify some reliable values for the coupling parameters.

[28] Equation (6) was obtained by using the continuity equation in an elementary volume [de Marsily, 1986]. During a pulse test, a mechanical stress is also applied on the chamber and the porous medium because the fluid pressure on the walls (or, equivalently, the seepage forces inside the medium) induces a new stress, and thus, the total stress is not constant during the test [Chapuis and Cazaux, 2002]. However, this effect is more important for elastic porous media [Chapuis and Cazaux, 2002] and is usually neglected in aquifers. Here the Callovo-Oxfordian is a weakly deformable compacted clay formation, where the change of stress will not have a major effect. This suggests that the effect of the variation of the total stress can be neglected and the continuity equation given by de Marsily [1986] can be used. In addition, the osmotic pressure gradient $(\nabla \Pi)$ in equation (6) is calculated using equation (3). This term requires the spatial distribution of solute concentrations to be accurately known.

[29] In weakly permeable media, ionic transport is dominated by the diffusive flux [Cey et al., 2001; Patriarche et al., 2004]. In equation (2) we therefore neglect the advection term $(c q \approx 0)$ and the kinematic dispersion; this assumption is consistent with the Peclet numbers obtained in this study (see section 4). In porous media, the general transport equation is [de Marsily, 1986]

$$
\operatorname{div}\left(J_{d}\right)=-\omega \frac{\partial c}{\partial t}
$$

where $J_{d}$ is the solute flux per unit surface of porous medium $\left(\mathrm{mol} \mathrm{m} \mathrm{m}^{-2} \mathrm{~s}^{-1}\right), c$ is the concentration in the porous medium $\left(\mathrm{mol} \mathrm{L}^{-1}\right)$, and $\omega$ is the total porosity.

[30] By combining equation (2) with the assumption discussed above and equation (7), one obtains the transport equation

$$
\nabla \cdot\left(\omega D_{p} \nabla c\right)=\omega \frac{\partial c}{\partial t}
$$

where $\omega$ is the porosity, $D_{p}$ is the diffusion coefficient in the porous medium $\left(\mathrm{m}^{2} \mathrm{~s}^{-1}\right), c$ is the concentration in the porous medium $\left(\mathrm{mol} \mathrm{L}^{-1}\right)$, and $t$ is the time (s). If the diffusive flux in the bound water is negligible, $\omega$ should be replaced by $\omega_{\text {eff }}$, i.e., the effective porosity (corresponding to the mobile water) in equations (7) and (8) in both the left-hand and right-hand terms.

[31] The variation of the pressure in the chamber is given by [Bredehoeft and Papadopulos, 1980]

$$
\frac{\partial P}{\partial t}=\frac{q_{c} S_{c}}{\beta_{c} V_{c}},
$$

where $P$ is the pressure in the chamber $(\mathrm{Pa}), S_{c}$ is the external surface area of the chamber $\left(\mathrm{m}^{2}\right), V_{c}\left(\mathrm{~m}^{3}\right)$ is the volume of water in the chamber, $q_{c}$ is the Darcy velocity crossing the vertical wall of the chamber (counted positive when directed toward the chamber), and $\beta_{c}\left(\mathrm{~Pa}^{-1}\right)$ is the compressibility of the chamber. The use of this compressibility instead of that of water $\beta_{l}$ has been proposed by Neuzil [1982] and Chapuis [1998] to take into account the compressibility of the whole chamber device (including internal tubing, fritting, and packers).

[32] The mass transport equation in the chamber is obtained by writing a solute mass balance across the vertical wall of the chamber:

$$
\left.S_{c} J_{d}\right|_{X(x, y) \in \Gamma_{c}}=V_{c} \frac{\partial C}{\partial t}
$$

where $C$ is the concentration in the chamber $\left(\mathrm{mol} \mathrm{L}^{-1}\right)$ and $\left.J_{d}\right|_{X(x, y) \in \Gamma c}$ is the diffusive flux across the vertical wall of the chamber (mol m $\mathrm{m}^{-2}$ ) given by equation (2), where $c q=0$, counted positive when directed toward the chamber.

[33] On the basis of the length to diameter ratio of the chamber (i.e., 10) [de Marsily, 1986] and the anisotropy of the intrinsic permeability, i.e., $k_{x} / k_{z} \simeq 1.5-3$ [Delay et al., 2006; Homand et al., 2006], the fluid flow can be considered two dimensional along the almost horizontal layer. Although radial coordinates might have been more appropriate for the problem posed here, the equations described in section 3.1 are treated in 2-D Cartesian coordinates $(x, y)$. These equations are solved on a square grid centered at the location of the chamber using a forward in time and central in space finite difference scheme. In order to obtain a greater accuracy, the mesh was refined around the chamber by a square-nested grid (see Figure 6). This approach was chosen because it allows a direct and convenient introduction of possible nonradial heterogeneities of the parameters. However, in the case of constant parameters or radial distributions, this 2-D model ought to give similar results to a $1-\mathrm{D}$ radial method. Since the $z$ component of the velocity is very weak, a 2-D $(r, z)$ model does not seem useful. The approximate character of a numerical modeling approach should be checked by a comparison of the numerical solution with available analytical solutions. This was done for the numerical solution developed in this study (see below).

[34] In this model, the fluxes are assumed to be horizontal, and thus, no vertical contributions to the fluxes are considered as upper and lower boundary conditions except through the source term $Q$. At a distance $L$ from the shut-in well location, the pressure and the concentration (equal to the formation pressure and concentration formation) are assumed constant and are prescribed as boundary conditions (Figure 6). The distance $L$ is chosen so that the pressure perturbation caused by the hydraulic or osmotic pulse does not reach this limit during the experiment. This ensures the relevance of the constant boundary conditions. One can use the characteristic time for a pressure perturbation propagation to determine a suitable value for the distance $L$. This characteristic time is $\tau=L^{2} / D_{h}$, with $D_{h}=\rho g k / \eta S_{s}$ being the diffusivity coefficient. If $\tau_{\text {exp }}$ denotes the expected duration of the experiment, an estimate of the length $L_{\text {exp }}$ corresponding to the arrival of the pressure perturbation at $\tau_{\exp }$ is $\left(\tau_{\exp } D_{h}\right)^{\frac{1}{2}}$. For instance, taking $D_{h}=10^{-7} \mathrm{~m}^{2} \mathrm{~s}^{-1}$ [Gonçalvès et al., 2004; Delay et al., 2006] and a value of 1 year for $\tau_{\text {exp }}$ yields a distance $L_{\exp }$ of $1.5 \mathrm{~m}$. Here $L$ is taken to be $10.5 \mathrm{~m}$, much above $L_{\text {exp }}$.

[35] The continuity between the porous medium and the chamber is maintained at the surface of the chamber $\left(\Gamma_{c}\right)$ by 


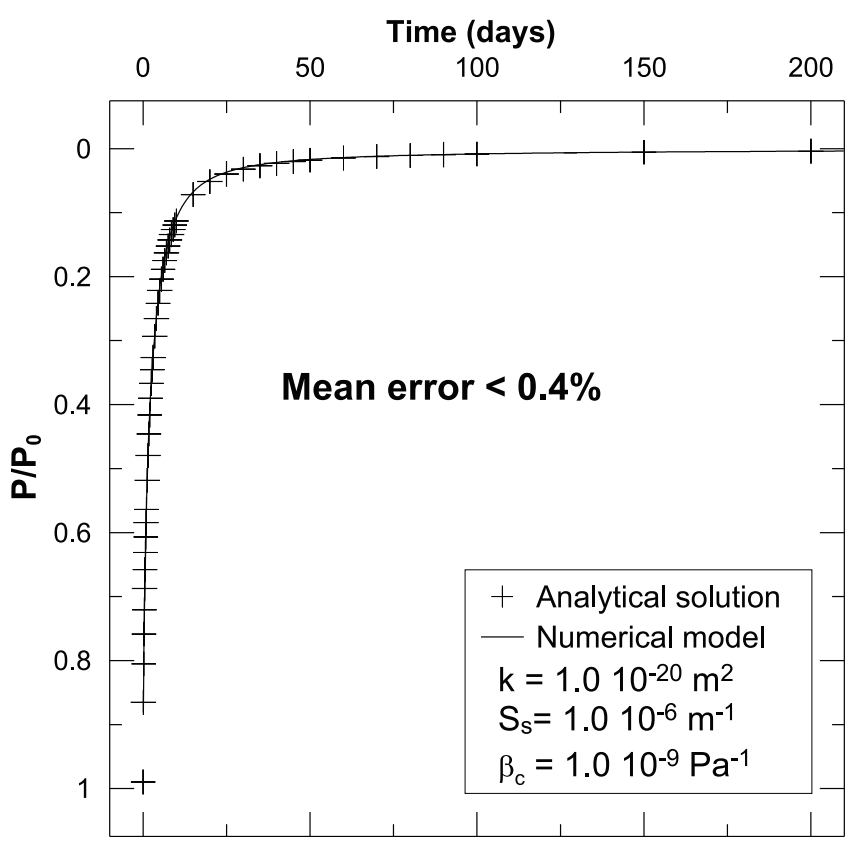

Figure 7. Response to a hydraulic pulse. Comparison between the response calculated by an analytical solution and by the numerical model.

defining special boundary conditions. The pressure and concentration in the chamber are equal to those in the adjacent porous medium (Figure 6).

[36] The present model can be used at different scales, e.g., for in situ experiments $(L \approx 10 \mathrm{~m})$ (see section 4$)$ or at the scale of cylindrical core samples $(L \approx 0.1 \mathrm{~m})$ [van der Kamp et al., 1996; Rousseau-Gueutin et al., 2009]. A validation of the model, without any source term $Q$, has been performed through a comparison with analytical solutions for an in situ hydraulic pulse [Bredehoeft and Papadopulos, 1980] (Figure 7) and an in situ chemical pulse [Gonçalvès, 2008] (Figure 8). For the hydraulic pulse, the numerical model and the analytical solution give the same result (error $<0.4 \%$ ). For the chemical pulse, the mean error is $<0.6) \%$. In this study, the numerical model is used to solve simultaneously the hydraulic and chemical components (equations (6) and (8)). Another advantage to using the numerical model stems from its ability to take into account a nonlinear dependence of some of the parameters with the concentration.

\subsection{Theoretical Analysis of a Chemical Pulse}

[37] The numerical model was used to perform numerical osmotic experiments to evaluate the contribution of each parameter in the osmotic response. The first analysis concerned five parameters: the storage coefficient, the intrinsic permeability, the compressibility of the chamber, the diffusion coefficient, and the osmotic efficiency coefficient. For this analysis, the osmotic efficiency coefficient was considered constant. A second analysis was performed to evaluate the effect of the spatial variation of this parameter as a function of the concentration variation. Table 2 lists the standard parameter values as well as the maximum and minimum values used in the analysis.

[38] The results obtained from these numerical experiments are presented in Figure 9. Dimensionless variables

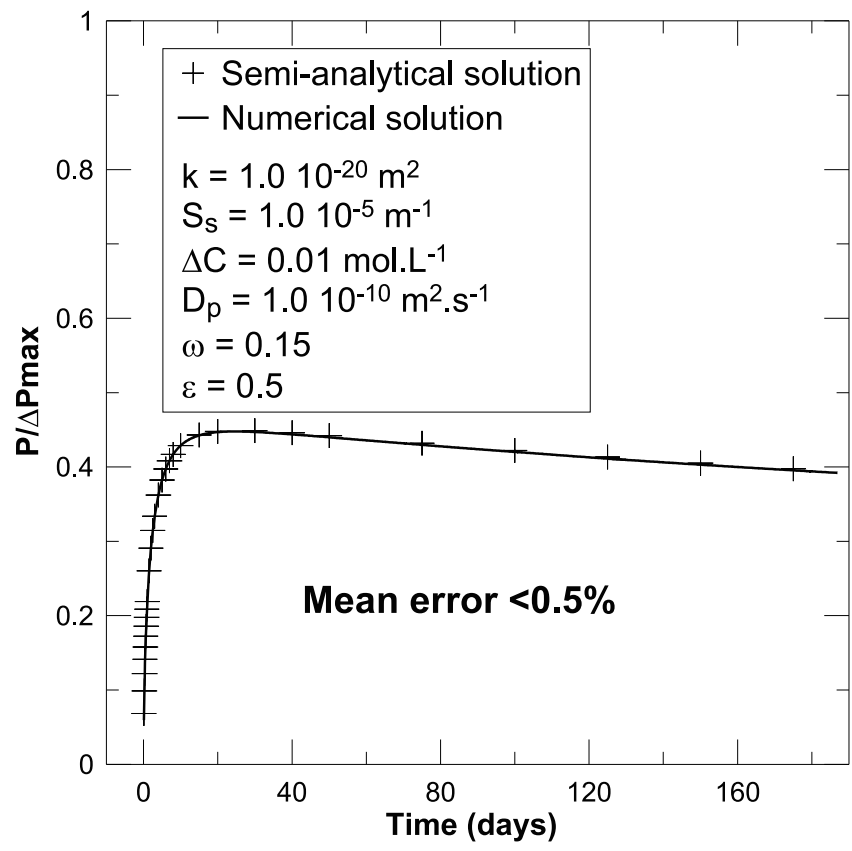

Figure 8. Response to a chemical pulse. Comparison between the response calculated by a semianalytical solution and by the numerical model.

$\left(\Delta P / \Delta P_{\max }\right.$ and $\left.\Delta C / \Delta C_{0}\right)$ are represented, where $\Delta P_{\max }$ is the maximum pressure difference given by $\nu R T \Delta C_{0}$, and $\Delta C_{0}$ is the initial value of $\Delta C$. The first simulation made with the standard parameter values is shown in Figure 9a. The osmotic efficiency obtained from $\varepsilon=\left(\Delta P^{m}\right) /\left(\nu R T \Delta C_{0}\right)$ (where $\Delta P^{m}$ is the maximum pressure measured during the experiment) is 0.44 instead of 0.5 , the value of $\varepsilon$ imposed in the model. Thus, this method gives a fairly good approximation of the osmotic efficiency (error around 6\%) if the pressure maximum is attained after a short time, i.e., if the concentration is weakly modified by diffusion.

[39] As shown in Figure 9, the chemical pulse exhibits different sensitivities according to which parameter is considered. For clarity, the chemical pulse is divided into three parts: (1) the pressure increase after the chemical perturbation, (2) the pressure maximum, and (3) the weakening of the pressure signal after the pressure maximum. These three stages are shown in Figure 9a. Thus, the three parts of the response are not sensitive to the same parameters.

[40] 1. The first part of the pressure increase is affected mainly by the permeability (Figure 9c) and the compressibility (Figure 9d). Thus, the slope of the first part describes principally the ratio between the permeability and the chamber compressibility. The effect of the osmotic efficiency coefficient (Figure 9f) seems negligible compared to the impact of these two parameters.

Table 2. Parameter Values Used in the Sensitivity Analysis of the Chemical Pulse

\begin{tabular}{lccc}
\hline Parameter & Low Value & Standard Value & High Value \\
\hline$D\left(\mathrm{~m}^{2} \mathrm{~s}^{-1}\right)$ & $1 \times 10^{-12}$ & $1 \times 10^{-11}$ & $1 \times 10^{-10}$ \\
$\varepsilon$ & 0.25 & 0.5 & 0.75 \\
$k\left(\mathrm{~m}^{2}\right)$ & $1 \times 10^{-21}$ & $1 \times 10^{-20}$ & $1 \times 10^{-19}$ \\
$S_{s}\left(\mathrm{~m}^{-1}\right)$ & $1 \times 10^{-7}$ & $1 \times 10^{-6}$ & $1 \times 10^{-5}$ \\
$\beta_{c}\left(\mathrm{~Pa}^{-1}\right)$ & $5 \times 10^{-10}$ & $1.5 \times 10^{-9}$ & $1 \times 10^{-8}$ \\
\hline
\end{tabular}



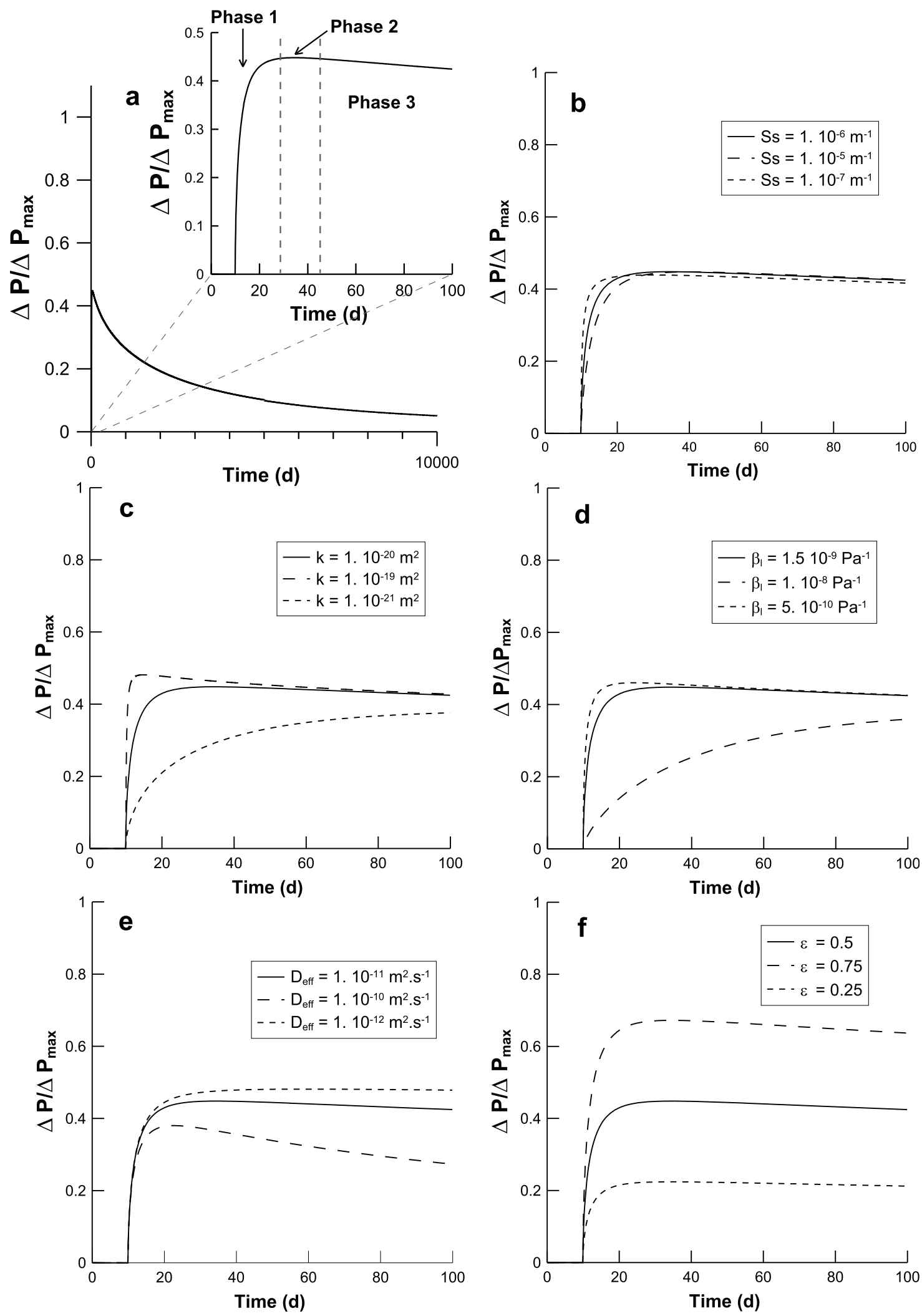

Figure 9. Sensitivity of the chemical pulse to different parameters. Results obtained with (a) the initial parameters, (b) a variation of storage coefficient, (c) a variation of the permeability, (d) variation of the compressibility, (e) a variation of diffusion coefficient, and (f) a variation of the osmotic efficiency. 


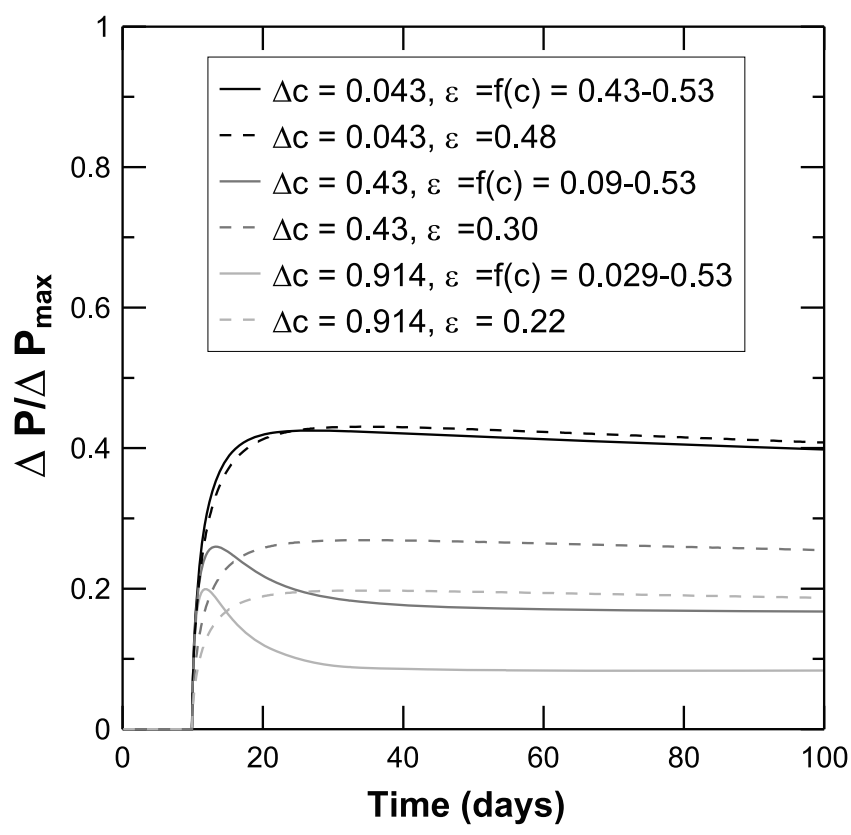

Figure 10. Sensitivity of the chemical pulse to concentration differences.

[41] 2. The second part of the osmotic pulse, which characterizes the pulse amplitude, is affected mostly by the osmotic efficiency (Figure 9f). The latter can therefore be deduced directly from the interpretation of this part.

[42] 3. The third part is mainly affected by the effective diffusion coefficient (Figure 9e) and less so by the osmotic efficiency coefficient (Figure 9f). The diffusion coefficient is thus given directly by the interpretation of this part of the curve.

[43] The specific storage coefficient (Figure 9b) has a negligible effect. These results are similar to those presented by Cruchaudet et al. [2008] and Gonçalvès [2008].

[44] In the previous numerical tests, a constant osmotic efficiency was assumed, but this coefficient is clearly dependent on the concentration and the pore size [Bresler, 1973]. To evaluate the impact of a constant coefficient assumption, we performed different sets of twin simulations for different values of the chemical pulse $\Delta C$, one with a constant coefficient and the other one with a variable coefficient. Note that the formation concentration is taken to be $0.086 \mathrm{~mol} \mathrm{~L}^{-1}$. Bresler's curve was used to introduce the dependence of $\varepsilon$ on $c$ (concentration in the porous medium).

[45] A first simulation was done with the standard values (Table 2) of the parameters and for a chemical pulse $\Delta C=$ $0.043 \mathrm{~mol} \mathrm{~L}^{-1}$. In this numerical experiment, the osmotic efficiency varies between 0.53 and 0.45 (Figure 10). A value of 0.5 was used for the simulation with a constant osmotic efficiency. The shapes of the two simulations are very similar (Figure 10). This suggests that for a weak variation of the concentration yielding a weak variation of the osmotic efficiency, the hypothesis of a constant coefficient could be correct.

[46] Two additional numerical experiments were performed with $\Delta C=0.43$ and $0.914 \mathrm{~mol} \mathrm{~L}^{-1}$. In these two experiments, according to Bresler's curve the osmotic efficiency varies between 0.52 and 0.13 for $\Delta C=0.43 \mathrm{~mol} \mathrm{~L}^{-1}$ and between 0.52 and 0.042 for $\Delta C=0.914 \mathrm{~mol} \mathrm{~L}^{-1}$. These two simulations, with a variable or a constant osmotic effi- ciency, give very different shapes (Figure 10). Indeed, the pressure decrease (section 3 ) shows a concave shape when a variable osmotic efficiency coefficient is used in the simulations. This concave shape becomes more pronounced as the concentration difference increases. Whatever its value, the use of a constant coefficient does not reproduce this shape, which characterizes the spatial variability of the concentration and thus that of the osmotic efficiency in the porous medium. In Figure 10, the calculations with the constant osmotic efficiency are made with the values $(0.30$ and 0.22 for $\Delta C=0.43$ and $0.914 \mathrm{~mol} \mathrm{~L}^{-1}$, respectively) which produce the correct pressure maximum.

[47] This analysis clearly shows that the more or less concave shape of the pressure response in time gives crucial information about the variability of the osmotic efficiency in the porous medium. According to our simulations, a linear shape of the pressure decrease would thus characterize a weak spatial variability of the osmotic efficiency, even in the case of important variations of the concentration.

\section{Interpretation of the Pore Pressure and Permeability Experiments at the ANDRA Underground Research Laboratory}

[48] The model presented in section 3 is used here to interpret the four osmotic experiments. Properly interpreted, the purely hydraulic signal, i.e., the pressure recovery phase, provides some values for the hydrodynamic parameters, i.e., the intrinsic permeability, the specific storage coefficient, and the formation pressure.

[49] In the numerical model, the chemical slugs are taken into account by an instantaneous alteration of the concentration in the chambers. Thus, we calculate the effects of the water exchange in chambers that are superimposed on the purely hydraulic effects. The volumes and compressibilities used in the simulations are listed in Table 3. In this study, the diffusion coefficients are not calibrated, and the diffusion coefficient is given by Descostes et al. [2008] for the anions and for the HTO, which is the maximum physically meaningful value, i.e., neutral species.

[50] Because of the sensitivity of the osmotic response to the spatial variability of the osmotic efficiency, which depends on the spatial distribution of the concentration (see section 3.3), two types of simulations were performed, with either a constant or a variable osmotic efficiency coefficient. The dependence of $\varepsilon$ on $c$ is introduced in the simulations using polynomial regressions of Bresler's curve (Figure 5). The osmotic coefficients are obtained from Bresler's curve by optimizing the pore size to minimize the error between the simulations and the measurements.

\subsection{First Set of Osmotic Tests: Chambers 1 and 3}

[51] For this first set of osmotic tests performed on 15 and 16 March 2006; the small amplitude, shown in Figure 4,

Table 3. Volumes and Compressibilities of the Chambers Used in the Simulations

\begin{tabular}{lcc}
\hline & Volume $\left(\mathrm{m}^{3}\right)$ & Compressibility $\left(\mathrm{Pa}^{-1}\right)$ \\
\hline Chamber 1 & $2.8 \times 10^{-3}$ & $1.02 \times 10^{-9}$ \\
Chamber 2 & $2.5 \times 10^{-3}$ & $1.25 \times 10^{-9}$ \\
Chamber 3 & $2.4 \times 10^{-3}$ & $1.65 \times 10^{-9}$ \\
Chamber 4 & $2.4 \times 10^{-3}$ & $1.80 \times 10^{-9}$ \\
\hline
\end{tabular}




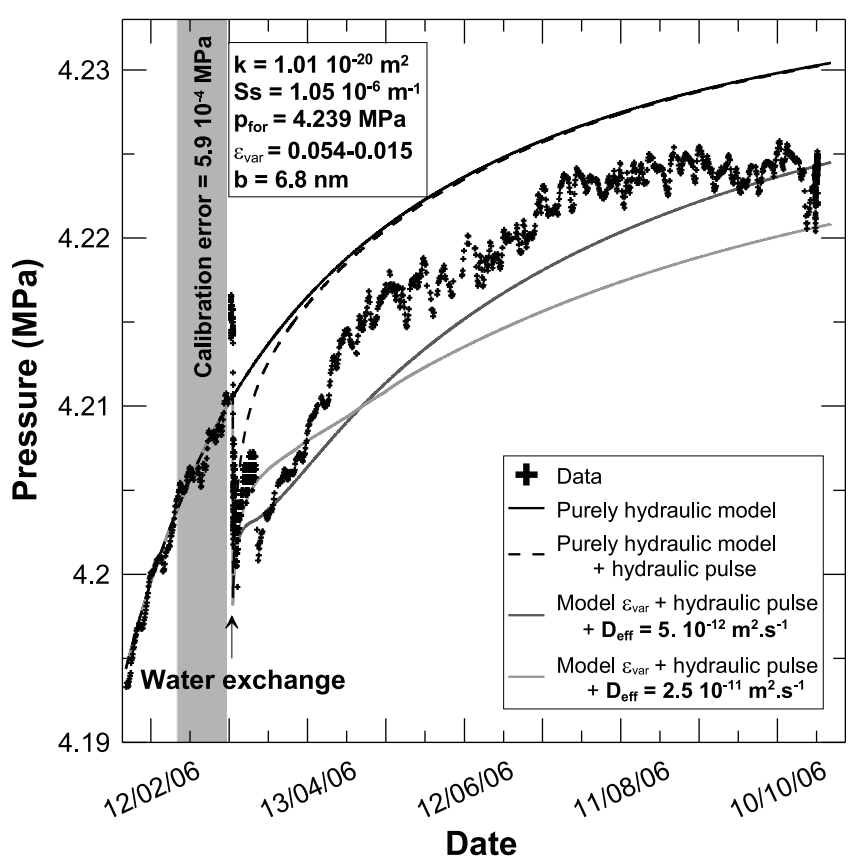

Figure 11. Results obtained for chamber 1 using a variable osmotic efficiency. The lowest value of this coefficient corresponds to the highest concentration (around $0.086 \mathrm{~mol} \mathrm{~L}^{-1}$ ), and its highest value corresponds to the lowest concentration (around $0.017 \mathrm{~mol} \mathrm{~L}^{-1}$ ). The solution in the chamber was replaced by one with a concentration of $1 \mathrm{~g} \mathrm{~L}^{-1}$ on $15 \mathrm{March}$ 2006.

requires that the hydraulic calibration is done with precision to identify, by difference with the hydraulic signal, a possible osmotic effect. The increase, after the change of water, of the difference between the measurements and the purely hydraulic simulations (pressure recovery) would thus suggest that the change of water, i.e., the chemical slug, had an effect.

[52] The calibration errors of the purely hydraulic model are on the order of $6 \times 10^{-4} \mathrm{MPa}$ (Figures 11 and 12). The calibrated permeabilities $\left(1.01 \times 10^{-20} \mathrm{~m}^{2}\right.$ and $7.95 \times 10^{-21}$ for chambers 1 and 3 , respectively) and specific storage coefficients $\left(1.05 \times 10^{-6} \mathrm{~m}^{-1}\right.$ and $6 \times 10^{-7} \mathrm{~m}^{-1}$ for chambers 1 and 3 , respectively) yield hydraulic diffusivity values on the order of $10^{-7} \mathrm{~m}^{2} \mathrm{~s}^{-1}$. The formation pressures inferred from these interpretations are 4.239 and 4.055 MPa for chambers 1 and 3 , respectively. The simulations give a good representation of the measurements (Figures 11 and 12, solid black line) before the water exchange and thus for the overall pressure recovery (Figure 4). After the chemical pulse, the difference between the pressure record and the hydraulic pulses simulated alone increases. This suggests that an osmotic process is at work.

[53] For chamber 1, a slight pressure drop occurs when the water is changed (Figure 11). The origin of this pressure drop was not well identified, and different origins will be discussed later. Consequently, it was imposed as a small hydraulic pulse $(-0.013 \mathrm{MPa})$. The pressures simulated with this hydraulic pulse adequately reproduce the beginning of the curve, but the pressure rises too quickly (Figure 11). This result indicates the presence of an osmotic process. The variable osmotic efficiency obtained from Bresler's curve varies between 0.054 for the lowest concentration (around
$0.017 \mathrm{~mol} \mathrm{~L}^{-1}$, i.e., $1 \mathrm{~g} \mathrm{~L}^{-1}$ in $\mathrm{NaCl}$ concentration) and 0.015 for the highest concentration (around $0.086 \mathrm{~mol} \mathrm{~L}^{-1}$ ). The simulation done with an effective diffusion coefficient of $2.5 \times 10^{-11} \mathrm{~m}^{2} \mathrm{~s}^{-1}$ [Descostes et al., 2008] reproduces the data satisfactorily.

[54] For chamber 3, the discrepancy between the simulated and the measured pressures is very small before the exchange of water (around 5.6 $\times 10^{-4} \mathrm{MPa}$, Figure 12). It increases after the water exchange, which indicates an osmotic response (Figure 12). Similarly to chamber 1 , a pressure drop occurred during the water exchange and was imposed in the model $(-0.18 \mathrm{MPa})$. The adjusted osmotic efficiency varies between 0.055 and 0.087 for the highest concentration (around $0.12 \mathrm{~mol} \mathrm{~L}^{-1}$, i.e., $7 \mathrm{~g} \mathrm{~L}^{-1}$ in the $\mathrm{NaCl}$ equation) and the lowest concentration (around $0.086 \mathrm{~mol} \mathrm{~L}^{-1}$ ). Both effective diffusion coefficients were tested, giving similar results. These simulations give similar results to those obtained with a constant osmotic efficiency $(\varepsilon=0.065)$.

[55] The simulations of this first set of in situ experiments required a high precision of the purely hydraulic component to identify the osmotic effects. A good precision was obtained by choosing a calibration period close to the time of the water exchange. This precision enables the identification of osmotic processes, although the response is weak. The chemical pulse simulations performed with a constant or a variable osmotic efficiency gave similar results.

\subsection{Second Set of Osmotic Tests: Chambers 2 and 4}

[56] This second series of osmotic tests was made on 25 and 26 October 2006 in chambers 2 and 4. The calibration

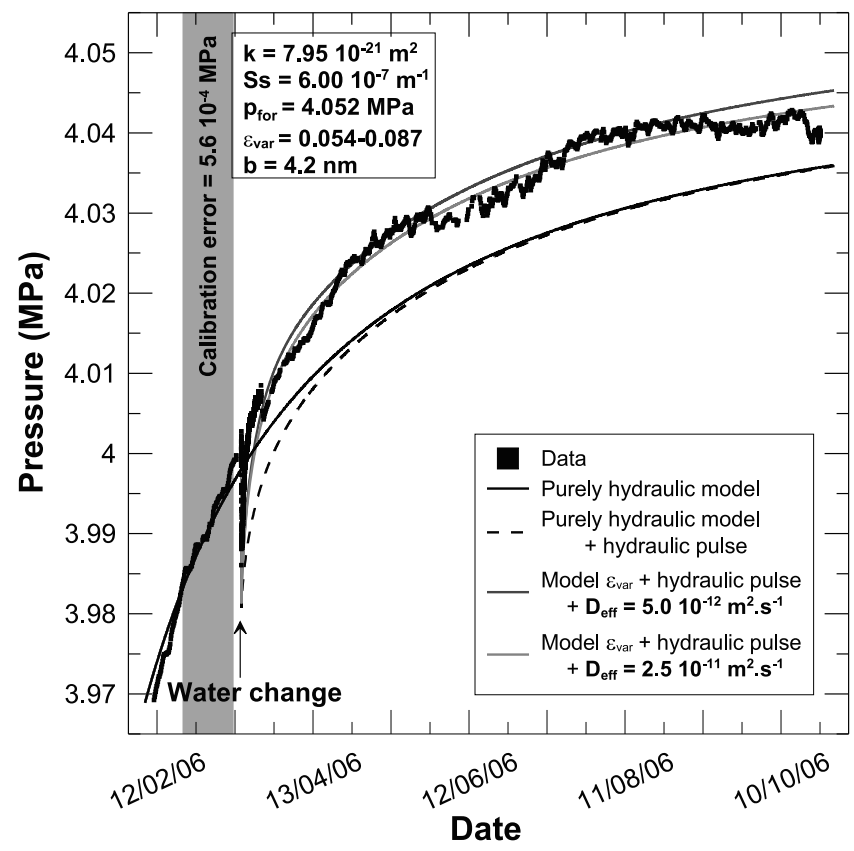

Figure 12. Results obtained for chamber 3 using a variable osmotic efficiency. The lowest value of this coefficient corresponds to the highest concentration (around $0.12 \mathrm{~mol} \mathrm{~L}^{-1}$ ), and its highest value corresponds to the lowest concentration (around $0.086 \mathrm{~mol} \mathrm{~L}^{-1}$ ). The solution in the chamber was replaced by one with a concentration of $7 \mathrm{~g} \mathrm{~L}^{-1}$ on $16 \mathrm{March}$ 2006. 


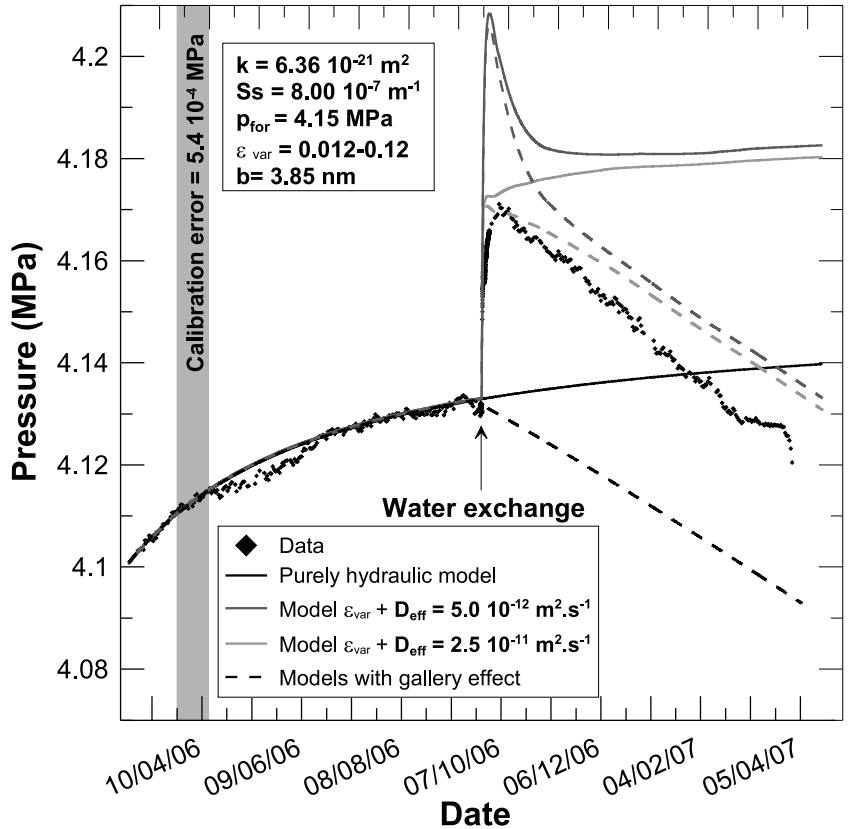

Figure 13. Results obtained for chamber 2 using a variable osmotic efficiency. The lowest value of this coefficient corresponds to the highest concentration (around $0.43 \mathrm{~mol} \mathrm{~L}^{-1}$ ), and its highest value corresponds to the lowest concentration (around $0.086 \mathrm{~mol} \mathrm{~L}^{-1}$ ). The exchange of water occurred on 25 October 2006; the new solution concentration is $25 \mathrm{~g} \mathrm{~L}^{-1}$.

errors obtained are on the order of $6 \times 10^{-4} \mathrm{MPa}$ (Figures 13 and 14). The calibrated intrinsic permeabilities, from $6.36 \times$ $10^{-21}$ to $7.52 \times 10^{-20} \mathrm{~m}^{2}$, and the specific storage coefficients $\left(8 \times 10^{-7}\right.$ to $\left.1.48 \times 10^{-6} \mathrm{~m}^{-1}\right)$ yield hydraulic diffusivity values on the order of $10^{-8}-10^{-7} \mathrm{~m}^{2} \mathrm{~s}^{-1}$ (Figures 13 and 14). The formation pressures are 4.15 and $3.902 \mathrm{MPa}$ for chambers 2 and 4, respectively.

[57] At the beginning of the pressure recovery, the simulations give a good representation of the measurements (Figure 4). After some time, the simulated pressures no longer agree with the measured ones. In fact, as observed in section 2.3 , the perturbation due to the galleries influences the pressure in the chambers. The perturbation is characterized by a discrepancy trend between the simulations and the measurements. Our model is based on the hypothesis of a constant formation pressure [Delay et al., 2007; Distinguin and Lavanchy, 2007]. However, it is crucial for interpreting the second series of osmotic tests that these pressure changes can be taken into account. This effect can be simulated by the use of a source term $Q$ in equation (6) (see section 3.2). Several simulations were carried out, ones without the source term, i.e., simulations without gallery effect, and others with the term source, i.e., simulations with the gallery effect.

[58] For the second series of chemical pulses (chambers 2 and 4), the results of the simulations are shown in Figures 13, 14, and 15. According to Figures 13-15, the simulations without the effect of the gallery do not reproduce accurately the data because of the presence of a nonsimulated decreasing trend of the pressure. Therefore, the simulations were performed with the source term calibrated on the data by fitting polynomial curves. For chamber 4 , this discharge rate could be quantified on the pressure record before the water change,

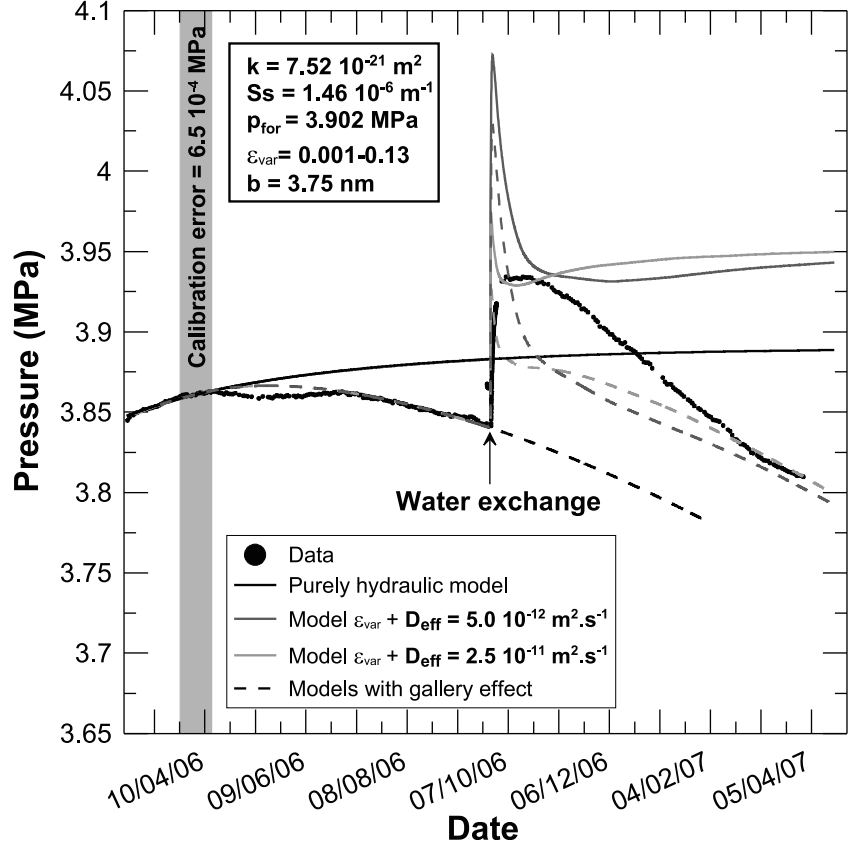

Figure 14. Results obtained for chamber 4 using a variable osmotic efficiency. The lowest value of this coefficient corresponds to the highest concentration (around $1.7 \mathrm{~mol} \mathrm{~L}^{-1}$ ), and its highest value corresponds to the lowest concentration (around $0.086 \mathrm{~mol} \mathrm{~L}^{-1}$ ). The initial solution was replaced by one with a concentration of $100 \mathrm{~g} \mathrm{~L}^{-1}$ on 26 October 2006.

and it was extrapolated after the change and applied to the simulated pressures. For chamber 2, however, the effect of the gallery becomes significant simultaneously with the osmotic test and, consequently, it is difficult to identify the time and

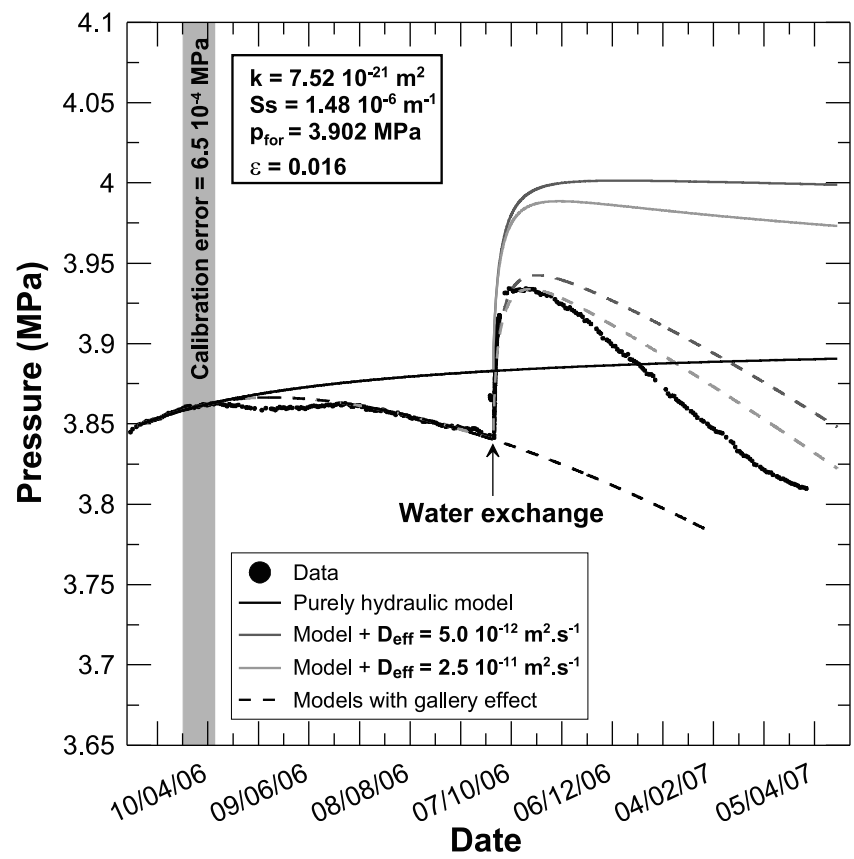

Figure 15. Results obtained for chamber 4 using a constant osmotic efficiency. 
Table 4. Hydrodynamic and Chemical Parameters Obtained From the Interpretations of the Hydraulic and Chemical Pulse Tests in the Four Shut-in Chambers

\begin{tabular}{lcccc}
\hline \multicolumn{1}{c}{ Parameter } & Chamber 1 & Chamber 2 & Chamber 3 & Chamber 4 \\
\hline$k\left(\mathrm{~m}^{2}\right)$ & $1.01 \times 10^{-20}$ & $6.36 \times 10^{-21}$ & $7.95 \times 10^{-21}$ & $7.52 \times 10^{-21}$ \\
$S_{s}\left(\mathrm{~m}^{-1}\right)$ & $1.05 \times 10^{-6}$ & $8.00 \times 10^{-7}$ & $6.00 \times 10^{-7}$ & $1.48 \times 10^{-6}$ \\
$D_{\text {eff }}\left(\mathrm{m}^{2} \mathrm{~s}^{-1}\right)$ & $2.5 \times 10^{-11}$ & $2.5 \times 10^{-11}$ & $5.00 \times 10^{-12}$ & $2.5 \times 10^{-11}$ \\
$\varepsilon$ & $0.015-0.054$ & $0.012-0.12$ & $0.054-0.087$ & 0.016 \\
$b(\mathrm{~nm})$ & 6.8 & 3.85 & 4.2 & - \\
$D_{\text {eff }}^{\mathrm{a}}\left(\mathrm{m}^{2} \mathrm{~s}^{-1}\right)$ & - & $2-3 \times 10^{-11}$ & - & $1-5 \times 10^{-11}$ \\
$\varepsilon^{\mathrm{a}}$ & - & $0.05-0.10$ & - & $0.12-0.18$ \\
$b^{\mathrm{a}}(\mathrm{nm})$ & - & $4.2-5$ & - & $3-4$ \\
\hline
\end{tabular}

a Obtained by Cruchaudet et al. [2008].

the amplitude of the effect from the measurements. The two magnitudes were deduced by interpolation of measurements made in the chambers on either side of chamber 2 (chambers 1 and 3). Figures 13, 14, and 15 represent the simulated pressures without the gallery effect (solid line) and the simulated pressures with the gallery effect (dashed line).

[59] For chamber 2 Figure 13 shows two distinct behaviors depending on the value of the diffusion coefficient. For a weak value of the diffusion coefficient $\left(D_{\text {eff }}=5 \times 10^{-12} \mathrm{~m}^{2}\right.$ $\mathrm{s}^{-1}$ ) the simulation is concave in shape, not shown by the measurements. The simulation made with a diffusion coefficient of $D_{\text {eff }}=2.510^{-11} \mathrm{~m}^{2} \mathrm{~s}^{-1}$ does not show a concave shape. It reproduces quite well the measurement with $\varepsilon=0.12$ at the lowest concentration (around $0.086 \mathrm{~mol} \mathrm{~L}^{-1}$ ) and $\varepsilon=$ 0.012 at the highest concentration (around $0.43 \mathrm{~mol} \mathrm{~L}^{-1}$, i.e., $25 \mathrm{~g} \mathrm{~L}^{-1}$ in $\mathrm{NaCl}$ concentration). This simulation gives similar results to those obtained using a constant osmotic efficiency of 0.031 .

[60] The results obtained for chamber 4 are presented in Figures 11 and 14. The data are not accurately reproduced by a variable osmotic efficiency (Figure 14); that is, the curves obtained are too concave in shape. A constant coefficient was used in alternative simulations (Figure 15), and the simulated pressures with the source term are consistent with the measured ones. The estimated osmotic coupling coefficient is 0.016 . With an effective diffusion coefficient of $2.5 \times$ $10^{-11} \mathrm{~m}^{2} \mathrm{~s}^{-1}$ (light gray in Figures 11, 14, and 15), the simulations are closer to the data.

[61] The importance of the diffuse flux compared to the advective flux in the mass transport equation could be determined by the calculation of the Peclet number, which is defined as

$$
P e=\frac{l q}{D_{\mathrm{eff}}},
$$

where $l$ is a characteristic length $(\mathrm{m}), q$ is Darcy's velocity (m $\mathrm{s}^{-1}$ ), and $D_{\text {eff }}$ is the diffusion coefficient. Darcy's velocity $q$ can be obtained from equation (9) and by determining directly $\partial P_{\text {max }} / \partial t$ from the measurements after the water exchange. This calculation was done for chamber 4 , where the highest concentration gradient is imposed, and thus, the assumption of a prominent diffusive flux could be questionable. A pressure difference, at the initial stage of the chemical pulse, of $93 \mathrm{kPa}$ in 8 days is observed, giving a Darcy velocity of $2.94 \times 10^{-12} \mathrm{~m} \mathrm{~s}^{-1}$. The Peclet numbers obtained are 0.117 and 0.0235 for the anion diffusion coefficient and for the HTO diffusion coefficient, respectively, and for a characteristic length of $0.2 \mathrm{~m}\left(l=\sqrt{t D_{h}}, t=10\right.$ days, and $D_{h}=5 \times$ $\left.10^{-8} \mathrm{~m}^{2} \mathrm{~s}^{-1}\right)$. The Peclet numbers obtained for this experiment justify the assumption of a prominent diffusive flux in the mass transport equation.

\section{Discussion}

[62] A new numerical model for the interpretation of hydraulic and chemical pulses in shut-in chambers in a compacted clay-rock was developed and used here to interpret osmotic in situ experiments. Two series of tests were carried out at the field scale.

[63] 1. The first series was characterized by low-amplitude chemical pulses. This made the interpretation difficult and required a very precise calibration of the purely hydraulic response linked to the drilling of the well.

[64] 2. The second set of data concerns a much greater response amplitude than the first one. However, for this data set, a 3-D effect, probably caused by the drilling of the laboratory gallery network, must be taken into account. The gallery network and the combined effects of all the galleries are quite complex and difficult to model. Here these 3-D effects were taken into account empirically by adding a point source calibrated on the data in the pressure diffusion equation.

[65] Despite the difficulties specific to each test series, the calibrations are quite satisfactory for all the chambers as well as the simulations of osmotic responses. The amplitude of the osmotic response depends mostly on the coefficient of osmotic efficiency, while the decay in pressure is controlled by diffusion (see section 3.3). This suggests that the estimates obtained here for the osmotic coupling coefficient are valid.

[66] The obtained permeabilities and storage coefficients are consistent with the in situ measurements performed by ANDRA in the PEP1001 borehole [Cruchaudet et al., 2008]. The resulting hydraulic diffusivities, on the order of $10^{-8}-$ $10^{-7} \mathrm{~m}^{2} \mathrm{~s}^{-1}$, agree well with the values in the literature [Gonçalvès et al., 2004; Delay et al., 2006]. Concerning the hydraulic pulses at the beginning of the water exchange in chambers 1 and 3, several explanations could be proposed. First of all, a thermal effect could be invoked because the exchange solutions were not at the same temperatures as the chambers [see Cruchaudet et al., 2008]. In this media the thermal effects could be important [Horseman and McEwen, 1996; Rousseau-Gueutin et al., 2009]. Second, a chemical compaction process could exist as the modification of the concentration can cause a modification of the electrochemical parameters such as the thickness of the diffuse layer. A simple hydraulic pulse, due to an imperfect control of the pressure during the water exchange, could be invoked as well.

[67] The results of the four chemical tests in this study indicate the presence of osmotic processes. The coefficients of osmotic efficiency obtained here are nevertheless relatively weak (between $1.2 \%$ and $12 \%$ ). The values are close to those observed in other argillaceous rocks [Neuzil, 2000; Noy et al., 2004; Garavito et al., 2007]. Consequently, the Callovo-Oxfordian formation shows a semipermeable membrane behavior, albeit weak for a concentration of $0.086 \mathrm{~mol} \mathrm{~L}^{-1}$ (Table 4). However, it is important to note that at the top of the Callovo-Oxfordian formation, the concentration is $0.017 \mathrm{~mol} \mathrm{~L}^{-1}$. For such a low concentration, and with a half pore size, i.e., $b=4 \mathrm{~nm}$, Bresler's curve predicts an osmotic efficiency on the order of $50 \%-70 \%$. The pore sizes obtained in this study ( $b=3.85$ and $4.2 \mathrm{~nm}$; see Table 4) are 
consistent with the measurements performed for the CallovoOxfordian shale, which give a main pore size class at $b=2-$ $3 \mathrm{~nm}$ [Gasc-Barbier, 2002; Leroy et al., 2007].

[68] The osmotic efficiency coefficient is a function of the concentration and decreases as the concentration increases [Bresler, 1973; Neuzil, 2000; Gonçalvès et al., 2004; Revil and Leroy, 2004]. The estimated coefficients in chambers 2,3 , and 4 show a decrease as the concentration rises. On the other hand, the coefficient measured in chamber 1 is lower than that measured in chamber 3 , although the concentration is seven times lower. This unexpectedly low coefficient suggests a possible effect of a disturbed zone around chamber 1 or the existence of localized fractures. The estimated coefficient in chamber 1 would then be representative of the disturbed zone and not of the undisturbed rock, which, in turn, indicates that the coefficient in the undisturbed rock would be higher.

[69] In a previous study on the osmotic origin of the overpressures in the Callovo-Oxfordian, Gonçalvès et al. [2004] used a pore size of $b=2 \mathrm{~nm}$ and Bresler's curve to calculate the osmotic efficiency. These results suggest the validity of the conclusions presented by Gonçalvès et al. [2004], i.e., a contribution of osmotic processes on the order of $0.1-0.15 \mathrm{MPa}$ to explain the pressure difference between the Callovo-Oxfordian and the adjacent aquifers, which is on the order of $0.2-0.5 \mathrm{MPa}$. Some additional calculations carried out by Rousseau-Gueutin [2008] show that the osmotic effect estimated in the Callovo-Oxfordian shale can explain $0.1 \mathrm{MPa}$ out of the $0.2-0.5 \mathrm{MPa}$ of the measured overpressures.

[70] The estimated diffusion coefficients (on samples and in situ) in the Callovo-Oxfordian are $5 \times 10^{-12} \mathrm{~m}^{2} \mathrm{~s}^{-1}$ for anions and $2.5 \times 10^{-11} \mathrm{~m}^{2} \mathrm{~s}^{-1}$ for tritiated water [Descostes et al., 2008]. Theoretically, the maximum value of the diffusion coefficient for the porous medium is the value obtained for tritiated water, i.e., no electrical interactions. For chamber 3 , these two coefficients give similar results, while for the three other chambers the diffusion coefficient for HTO gives the best results.

[71] In the cases of chambers 2 and 4, several explanations can be proposed. First, the concentrations used in the two tests are much higher than the formation concentration (5-20 times more concentrated). Revil et al. [2005] have demonstrated theoretically that there is a relation between the effective diffusion coefficient and the concentration. The effective diffusion coefficient increases when the concentration increases until a plateau is reached [see Revil et al., 2005, Figure 14]. For concentrations equivalent to those used in these tests, these authors obtained diffusion coefficients on the order of $10^{-10} \mathrm{~m}^{2} \mathrm{~s}^{-1}$ for clays. Thus, the high effective diffusion coefficients may be due to the high concentrations used in chambers 2 and 4 . It is also possible that the perturbed zone around the well locally modifies the transport in the surrounding medium. Thus, the simulated effective diffusion coefficients, as well as the osmotic efficiency coefficients, may be characteristic of a disturbed zone around the well. The size of these perturbed zones around the wells is on the order of the well diameter [Matray et al., 2007].

[72] The first explanation does not apply to chamber 1 . The concentration in the chamber is too weak to cause such an effect. However, the effect of the disturbed zone is plausible and consistent with a weak osmotic efficiency coefficient. These considerations suggest that the calibrated parameters for chamber 1 are more likely to be representative of a disturbed zone.

[73] The simulations performed with a constant or a variable osmotic efficiency coefficient give similar results for chambers 1,2, and 3 . The weak variation of the osmotic efficiency in the porous medium explains this agreement between the two simulations. The osmotic experiments carried out in chamber 4 are more accurately reproduced by a constant coefficient, characteristic of a weak variation of $\varepsilon$. Indeed, the simulations performed with a variable osmotic efficiency show an exaggerated concavity of the pressure decrease as compared to the measurements. In the numerical model, the variation of the osmotic efficiency is accounted for using Bresler's curve. This discrepancy between the data and the simulations suggests that this curve cannot properly predict the behavior of the natural clay-rocks for low osmotic efficiency or for high value of $b \sqrt{c}$. These results are in good agreement with the conclusions of Neuzil and Provost [2009] on the nonuniversality of Bresler's curve.

\section{Conclusions}

[74] This experimental study was principally motivated by the necessity to estimate of osmotic coefficients in the Callovo-Oxfordian shales in order to evaluate the relative importance of osmotic processes in the measured overpressures in this geological formation. Four in situ experiments were performed to estimate this coefficient. A numerical model was developed to interpret hydraulic and chemical pulses in shut-in chambers. In this model a specific mass balance equation was introduced to simulate the evolution of the pressure in the measurement chamber. An important result is obtained by comparing the simulations performed with a constant and a variable osmotic efficiency. This comparison clearly shows that the shape of the pressure decrease during an osmotic test is controlled by the spatial variability of the osmotic coefficient in the porous medium. This variability is a function of the concentration and the pore size. Some improvements of the model, such as the introduction of the swelling pressure, are left for future developments. Nevertheless, the osmotic experiments are well represented by this model. A range of $0.012-0.12$ was obtained for the osmotic efficiency in the Callovo-Oxfordian. These values can only explain $0.1-0.15 \mathrm{MPa}$ of the $0.2-$ $0.5 \mathrm{MPa}$ measured overpressures in the Callovo-Oxfordian.

[75] Acknowledgments. The French National Center for Scientific Research (CNRS) through the scientific program PEER and the French Nuclear Waste Agency, ANDRA, are acknowledged for their financial support. We also thank the Editor, Associate Editor, and four anonymous reviewers for comments that helped to significantly improve this manuscript.

\section{References}

Agence Nationale Pour la Gestion des Déchets Radioactifs (ANDRA) (2005), Callovo-Oxfordien, rapport de synthèse, technical report, Lab. de Rech. Souterrain de Meuse/Haute Marne, Chatanay-Malabry, France.

Bader, S., and H. Kooi (2005), Modelling of solute and water transport in semi-permeable clay membranes: Comparison with experiments, $A d v$. Water Resour., 28, 203-214.

Bolt, G. H. (Ed.) (1979), Soil Chemistry, vol. B, Physico-Chemical Models, Elsevier, Amsterdam.

Bredehoeft, J. D., and S. S. Papadopulos (1980), A method for determining the hydraulic properties of tight formations, Water Resour. Res., 16(1), 233-238. 
Bresler, E. (1973), Anion exclusion and coupling effects in nonsteady transport unsatured soils: I. Theory, Soil Sci. Soc. Am. Proc., 37(5), 663-669.

Cey, B., S. L. Barbour, and M. J. Hendry (2001), Osmotic flow through a Cretaceous clay in southern Saskatchewan, Canada, Can. Geotech. J., $38,1025-1033$.

Chapuis, R. P. (1998), Overdamped slug test in monitoring wells: Review of interpretation methods with mathematical, physical, and numerical analysis of storativity influence, Can. Geotech. J., 35, 697-719.

Chapuis, R. P., and D. Cazaux (2002), Pressure-pulse test for field hydraulic conductivity of soils: Is the common interpretation method adequate?, in Evaluation and Remediation of Low Permeability and Dual Porosity Environments, edited by M. N. Sara and L. G. Everett, pp. 66-82, ASTM Int., West Conshohocken, Pa.

Cruchaudet, M., J. Croisé, and J.-M. Lavanchy (2008), In situ osmotic experiment in the Callovo-Oxfordian argillaceous formation at the Meuse/Haute-Marne URL (France): Data and analysis, Phys. Chem. Earth, 33, S114-S124.

Delay, J., A. Trouiller, and J.-M. Lavanchy (2006), Propriétés hydrodynamiques du Callovo-Oxfordien dans l'est du bassin de Paris: Comparaison des résultats obtenus selon différentes approches, C. R. Geosci., $338,892-907$.

Delay, J., A. Vinsot, J.-M. Krieguer, H. Rebours, and G. Armand (2007), Making of the underground scientific experimental programme at the Meuse/Haute-Marne underground research laboratory, north eastern France, Phys. Chem. Earth, 32, 2-18.

de Marsily, G. (1986), Quantitative Hydrogeology: Groundwater Hydrology for Engineers, Academic, New York.

Descostes, M., et al. (2008), Diffusion of anionic species in Callovo-Oxfordian argillites and Oxfordian limestones (Meuse/Haute-Marne, France), Appl. Geochem., 23, 655-677.

Distinguin, M., and J.-M. Lavanchy (2007), Determination of hydraulic properties of the Callovo-Oxfordian argillite at the Bure site: Synthesis of the results obtained in deep boreholes using several in situ investigation technniques, Phys. Chem. Earth, 32, 379-392.

Fritz, S. J. (1986), Ideality of clay membranes in osmotic processes: A review, Clays Clay Miner., 34(2), 214-223.

Fritz, S. J., and I. W. Marine (1983), Experimental support for a predictive osmotic model of clay membranes, Geochim. Cosmochim. Acta, 47, $1515-1522$.

Garavito, A., I. De Cannière, and H. Kooi (2007), In situ chemical osmosis experiment in the Boom clay at the Mol underground research laboratory, Phys. Chem. Earth, 32, 421-433.

García-Gutiérreza, M., J. Cormenzanab, T. Missanaa, M. Mingarroa, U. Alonsoa, J. Samperc, Q. Yangc, and S. Yic (2008), Diffusion experiments in Callovo-Oxfordian clay from the Meuse/Haute-Marne URL, France. Experimental setup and data analyses, Phys. Chem. Earth, 33, S125-S130.

Gasc-Barbier, M. (2002), Etude des mécanismes de déformation des roches argileuses profondes: Apport de la microstructure et des analyses pétrophysiques, Ph.D. thesis, Univ. Pierre et Marie Curie, Paris.

Gaucher, E., et al. (2004), ANDRA underground research laboratory: Interpretation of the mineralogical and geochemical data acquired in the Callovo-Oxfordian formation by investigative drilling, Phys. Chem. Earth, 29, 55-77.

Gonçalvès, J. (2008), A slug test to assess the osmotic and hydraulic properties of argillaceous formations, Water Resour. Res., 44, W07501, doi:10.1029/2007WR006547.

Gonçalvès, J., S. Violette, and J. Wendling (2004), Analytical and numerical solutions for alternative overpressuring processes: Application to the Callovo-Oxfordian sedimentary sequence in the Paris basin, France, J. Geophys. Res., 109, B02110, doi:10.1029/2002JB002278.

Gonçalvès, J., P. Rousseau-Gueutin, and A. Revil (2007), Introducing interacting diffuse layers in TLM calculations. A reappraisal of the influence of the pore size on the swelling pressure and the osmotic efficiency of compacted bentonites, J. Colloid Interface Sci., 316, 92-99.

Homand, F., J.-F. Shao, A. Giraud, C. Auvray, and D. Hoxha (2006), Pétrofabrique et propriétés mécaniques des argilites, C. R. Geosci., 338, 882-891.

Horseman, S., and T. McEwen (1996), Thermal constraints on disposal of heat-emitting waste in argillaceous rocks, Eng. Geol., 41(1-4), 5-16.

Horseman, S. T., J. J. W. Higgo, J. Alexander, and J. F. Harrington (1996), Water, gas and solute movement through argillaceous media, Nucl. Energy Agency, Montpellier, France.

Horseman, S., J. Harrington, and D. Noy (2007), Swelling and osmotic flow in a potential host rock, Phys. Chem. Earth, 32, 408-420.
Katchalsky, A., and P. F. Curran (1967), Nonequilibrium Thermodynamics in Biophysics, Harvard Univ. Press, Cambridge, Mass.

Keijzer, T. J. S. (2000), Chemical osmosis in natural clayey materials, Ph.D. thesis, Utrecht Univ., Utrecht, Netherlands.

Keijzer, T. J. S., P. J. Kleingeld, and J. P. G. Loch (1999), Chemical osmosis in compacted clayey material and the prediction of water transport, Eng. Geol., 53, 151-159.

Kemper, W. D., and J. P. Quirk (1972), Ion mobilities and electric charge of external clay surfaces inferred from potential differences and osmotic flow, Soil Sci. Soc. Am. Proc., 36, 426-433.

Kemper, W. D., and J. B. Rollins (1966), Osmotic efficiency coefficients across compacted clays, Soil Sci. Soc. Am. Proc., 30(5), 529-534.

Leroy, P., A. Revil, S. Altmann, and C. Tournassat (2007), Modeling the composition of the pore water in a clay-rock geological formation (Callovo-Oxfordian, France), Geochim. Cosmochim. Acta, 71, 10871097.

Malusis, M. A., and C. D. Shackelford (2002a), Coupling effects during steady-state solute diffusion through a semipermeable clay membrane, Environ. Sci. Technol., 36, 1312-1319.

Malusis, M. A., and C. D. Shackelford (2002b), Theory for reactive solute transport through clay membrane barriers, J. Contam. Hydrol., 59, 291316.

Malusis, M. A., and C. D. Shackelford (2004), Explicit and implicit coupling during solute transport through clay membrane barriers, J. Contam. Hydrol., 72, 259-285.

Manassero, M., and A. Dominijanni (2003), Modelling the osmotic effect on solute migration through porous media, Géotechnique, 53, 481-492.

Marine, I. W., and S. J. Fritz (1981), Osmotic model to explain anomalous hydraulic heads, Water Resour. Res., 17(1), 73-82.

Matray, J.-M., S. Savoye, and J. Cabrera (2007), Desaturation and structure relationships around drifts excavated in the well-compacted Tournemire's argillite (Aveyron, France), Eng. Geol., 9, 1-16.

Melkior, T., S. Yahiaoui, D. Thoby, S. Motellier, and V. Barthes (2007), Diffusion coefficients of alkaline cations in Bure mudrock, Phys. Chem. Earth, 32, 453-462.

Mitchell, J. K. (1993), Fundamentals of Soil Behavior, John Wiley, New York.

Moyne, C., and M. A. Murad (2002), Electro-chemo-mechanical couplings in swelling clays derived from a micro/macro-homogenization procedure, Int. J. Solids Struct., 39, 6159-6190.

Neuzil, C. E. (1982), On conducting the modified "slug" test in tight formation, Water Resour. Res., 18(2), 439-441.

Neuzil, C. E. (1986), Groundwater flow in low permeability environments, Water Resour. Res., 22(8), 1163-1195.

Neuzil, C. E. (1995), Abnormal pressures as hydrodynamic phenomena, Am. J. Sci., 295, 742-786.

Neuzil, C. E. (2000), Osmotic generation of 'anomalous' fluid pressures in geological environments, Nature, 403, 182-184.

Neuzil, C. E., and A. M. Provost (2009), Recent experimental data may point to a greater role for osmotic pressures in the subsurface, Water Resour. Res., 45, W03410, doi:10.1029/2007WR006450.

Noy, D., S. Horseman, J. Harrington, P. Bossart, and H. Fish (2004), An experimental and modelling study of chemico-osmosis effect in the Opalinus clay of Switzerland, pp. 95-126, Off. Fed. des Eaux et de la Geol., Bern.

Olsen, H. W. (1969), Simultaneous fluxes of liquid and charge in saturated kaolinite, Soil Sci. Soc. Am. Proc., 33, 338-344.

Patriarche, D., E. Ledoux, R. Simon-Coincon, J.-L. Michelot, and J. Cabrera (2004), Characterization and modeling of diffusion process for mass transport through the Tournemire argillites (Aveyron, France), Appl. Clay Sci., 26(1-4), 109-122.

Revil, A. (1999), Ionic diffusivity, electrical conductivity, membrane and thermoelectric potentials in colloids and granular porous media: A unified model, J. Colloid Interface Sci., 212, 503-522.

Revil, A., and P. Leroy (2004), Constitutive equations for ionic transport in porous shales, J. Geophys. Res., 109, B03208, doi:10.1029/ 2003JB002755.

Revil, A., and M. Pessel (2002), Electroosmotic flow and the validity of the classical Darcy equation in silty shales, Geophys. Res. Lett., 29(9), 1300, doi:10.1029/2001GL013480.

Revil, A., P. Leroy, and K. Titov (2005), Characterization of transport properties of argillaceous sediments: Application to the Callovo-Oxfordian argillite, J. Geophys. Res., 110, B06202, doi:10.1029/ 2004JB003442.

Rousseau-Gueutin, P. (2008), Les processus couplés dans les argilites du Callovo-Oxfordien sur le site de Bure: Implications pour les mouve- 
ments de fluide et de solutés, Ph.D. thesis, Univ. Pierre et Marie Curie, Paris.

Rousseau-Gueutin, P., J. Gonçalvès, and S. Violette (2008), Osmotic efficiency in Callovo-Oxfordian argillites: Experimental vs. theoretical models, Phys. Chem. Earth, 33, S106-S113.

Rousseau-Gueutin, P., V. de Greef, J. Gonçalvès, S. Violette, and S. Chanchole (2009), Experimental device for chemical osmosis measurement on natural clay-rock samples maintained at in situ conditions: Implications for formation pressure interpretations, J. Colloid Interface Sci., $337,106-116$.

Soler, J. M. (2001), The effect of coupled transport phenomena in the Opalinus clay and implications for radionuclide transport, J. Contam. Hydrol., 53, 63-84.

Staverman, A. J. (1952), Non-equilibrium thermodynamics of membrane processes, Trans. Faraday Soc., 48, 176-185.
Tsang, C.-F., P. Blumling, and F. Bernier (2008), Coupled hydro-mechanical processes in crystalline rock and indurated and plastic clays: A comparative discussion, Lawrence Berkeley Natl. Lab., Berkeley, Calif.

van der Kamp, G., D. Van Stempvoort, and L. Wassenaar (1996), The radial diffusion method: 1. Using intact cores to determine isotopic composition, chemistry, and effective porosities for groundwater in aquitards, Water Resour. Res., 32(6), 1815-1822.

M. Cruchaudet, ANDRA, Route départementale, F-55290 Bure, France. (martin.cruchaudet@andra.fr)

G. de Marsily, J. Gonçalvès, and S. Violette, Sisyphe, UMR 7619, Université Pierre et Marie Curie, 4 Pl. Jussieu, F-75005 Paris, France. (gdemarsily@aol.fr; julio.goncalves@upmc.fr; sophie.violette@upmc.fr)

P. Rousseau-Gueutin, School of the Environment, Flinders University, GPO Box 2100, Adelaide, SA 5001, Australia. (pauline.gueutin@ flinders.edu.au) 